\title{
Immunomodulation targeting of both $A \beta$ and tau pathological conformers ameliorates Alzheimer's disease pathology in TgSwDI and 3xTg mouse models
}

Fernando Goñi ${ }^{1}$, Krystal Herline ${ }^{1}$, Daniel Peyser ${ }^{1}$, Kinlung Wong ${ }^{1}$, Yong Ji ${ }^{1,5}$, Yanjie Sun ${ }^{1}$, Pankaj Mehta ${ }^{4}$ and Thomas Wisniewski ${ }^{1,2,3,6^{*}}$

\begin{abstract}
Background: Central to the pathogenesis of Alzheimer's disease (AD) and many other neurodegenerative diseases is the conformational change of a normal self-protein into toxic oligomeric species and amyloid deposits. None of these disorders have an effective therapy, but immunization approaches hold great promise. We have previously shown that active immunization with a novel peptide when polymerized into a stable oligomeric conformation, pBri, induced a humoral immune response to toxic A $\beta$ species in an AD model, APP/PS1 transgenic ( $\mathrm{Tg}$ ) mice, reducing plaque deposits. pBri is a glutaraldehyde polymerized form of the carboxyl fragment of an amyloidogenic protein, which is deposited in the brains of patients with a rare autosomal dominant disease due to a missense mutation in a stop codon, resulting in the translation of an intronic sequence, with no known sequence homology to any mammalian protein.
\end{abstract}

Methods: In the current study we tested whether pBri-peptide-based immunomodulation is effective at reducing both vascular amyloid deposits and tau-related pathology using TgSwDI mice with extensive congophilic angiopathy and $3 x \operatorname{Tg}$ mice with tau pathology.

Results: Our results indicate that this immunomodulation approach, which produces a humoral response to proteins in a pathological conformation, is effective at reducing both $A \beta$ and tau-related pathologies.

Conclusions: This immunomodulatory approach has the advantage of using a non-self-immunogen that is less likely to be associated with autoimmune toxicity. Furthermore we found that it is able to target all the cardinal features of AD concurrently.

Keywords: Alzheimer's disease, British amyloidosis, $\beta$-sheet conformation, amyloid, vaccination, transgenic mice

\section{Introduction}

Alzheimer's disease (AD) is the most common cause of dementia globally, affecting approximately 36 million people currently and approximately 115 million by 2050 [1]. Presently available treatments have minimal or no effect on the course of the disease. Numerous novel therapeutic strategies are being developed, with active and

\footnotetext{
* Correspondence: Thomas.wisniewski@nyumc.org

'Department of Neurology, New York University School of Medicine, 550

First Avenue, New York, NY 10016, USA

${ }^{2}$ Department of Pathology, New York University School of Medicine, 550 First Avenue, New York, NY 10016, USA

Full list of author information is available at the end of the article
}

passive immunization being among the most advanced approaches [2-6]. The neuropathology of $A D$ consists of the accumulation of amyloid $\beta(A \beta)$ as amyloid plaques and congophilic amyloid angiopathy (CAA), as well as the accumulation of aggregated, phosphorylated tau as neurofibrillary tangles [7]. The most toxic species of $A \beta$ and aggregated tau are thought to be oligomeric, with both of these pathologies potentially spreading via extracellular soluble oligomers in a prion-like mechanism [8-10]. A $\beta$ and tau oligomers, as well as amyloid plaques and neurofribrillary tangles (NFTs), share many structural and biophysical properties, such as a high $\beta$-sheet content, 
resistance to proteolytic degradation and neuronal toxicity. It has also been shown that $A \beta$ and tau-related pathology can, under some conditions, seed or propagate each other.

Immunotherapy is very effective for both $\mathrm{AD}$ and prion diseases, at least in mouse models [11,12]. Unfortunately, two recent phase III trials of passive immunization for AD failed to achieve benefit by their primary end points [13]. To develop a highly successful immunotherapy for AD patients, several problems need to be overcome including: avoiding excessive cell-mediated immunity, which has been linked to autoimmune encephalitis; reducing CAA deposition without inducing associated microhemorrhages and/ or vasogenic edema; reducing tau-related pathology, which is known to correlate with clinical status better than amyloid deposits, and targeting of oligomeric species, which are the most toxic [3]. To concurrently address all these issues we sought to develop therapeutic immunomodulation through a novel active immunization approach that specifically targets the pathological $\beta$-sheet conformation that is shared by $A \beta$ and tau-disease-associated species. We used a polymerized British amyloidosis (pBri) related peptide in a predominantly $\beta$-sheet, in an oligomeric form, prepared using glutaraldehyde in a controlled manner. British amyloidosis (ABri) is a rare form of familial human amyloidosis associated with a missense mutation in a stop codon. This mutation results in the transcription of an intronic sequence, leading to the production of a highly amyloidogenic protein with a carboxyl terminus that has no sequence homology to any other native human protein, including $\mathrm{A} \beta$ and tau [14-16].

We hypothesized that through conformational mimicry the polymerized oligomeric pBri peptide, which corresponds to the carboxyl terminus of ABri, could induce a conformation-selective immune response that will recognize $A \beta$, as well as aggregated phosphorylated tau. Such an immunostimulatory approach would have a reduced risk of inducing autoimmune complications as it is specific to pathological conformers and the immunogen has no sequence homology to any known mammalian protein or peptide. In a prior study we tested this approach in an APP/PS1 AD mouse model with extensive amyloid plaque deposition [16] and evaluated for behavioral benefits and reductions in $A \beta$-related pathology histologically and biochemically. We showed that this immunomodulation targeting a pathological conformation of $\mathrm{A} \beta$ was highly effective at reducing amyloid plaques, correlating with behavioral rescue. The polyclonal antibody response obtained in the vaccinated mice specifically recognized plaques and dystrophic neurites in human brain tissue [16]. This novel therapeutic approach was commented on as a promising new direction for $\mathrm{AD}$ vaccination [17]. In the current study we addressed the critical issues of whether this type of approach could be used for both CAA and tau-related pathology, without any associated toxicity. To assess for effects on vascular amyloid and NFT-related pathology we used TgSwDI mice, which are a well-characterized model of CAA, and 3xTg mice with tau pathology, respectively $[18,19]$. We hypothesized that for immunomodulation to be highly successful it needs to target all the cardinal lesions of $\mathrm{AD}$ concurrently, that is amyloid plaques, CAA and NFT. Furthermore, to reduce the possibility of autoimmune complications, the immunogen needs to be a non-self-antigen in a conformation that induces an immune response that specifically targets pathological conformers. The evaluation of the effectiveness of our novel immunomodulatory approach in a variety of $\mathrm{AD}$ mouse models, which mimic different aspects of the human disease, is a critical step before any clinical testing.

\section{Materials and methods}

\section{Synthesis of peptide, polymerization of the Bri peptide and assessment of conformation}

This was done as previously published [16]. In brief, the 13 residue peptide corresponding to the carboxyl terminus of ABri (Cys-Ser-Arg-Thr-Val-Lys-Lys-Asn-Ile-Ile-Glu-Glu-Asn) was synthesized on an ABI 430A peptide synthesizer (AME Bioscience, Chicago, IL) at the Keck peptide synthesis facility at Yale University, CT. Mass spectroscopy of the lyophilized end-product was used to verify the expected molecular weight. To make the 13-residue Bri peptide immunogenic and to have a stable oligomeric conformation, the peptide was subjected to controlled polymerization using the following protocol.

The peptide was dissolved at $3 \mathrm{mg} / \mathrm{ml}$, in $100 \mathrm{mM}$ borate buffer saline (BBS), pH 7.4. Fresh $1 \%$ glutaraldehyde in BBS was prepared and added to the peptide to a final $5 \mathrm{mM}$ glutaraldehyde concentration and incubated in an Eppendorf block shaker at $800 \mathrm{rpm}$ and $56^{\circ} \mathrm{C}$ for $16 \mathrm{~h}$. The solution was then quenched with $0.5 \mathrm{M}$ glycine to make the solution $100 \mathrm{mM}$ in glycine. After $5 \mathrm{~min}$, the solution was diluted 1:3 with BBS, dialyzed against $2 \mathrm{mM} \mathrm{BBS}$ overnight at $4^{\circ} \mathrm{C}$, aliquoted and lyophilized. To determine the degree of aggregation the original monomeric Bri peptide and polymerized Bri (pBri) were electrophoresed on 12.5\% sodium dodecyl sulfate (SDS)-polyacrylamide tris-tricine gels under reducing conditions. Western blots were performed with a rabbit anti-ABri polyclonal Ab [16] (1:1,000 dilution). The secondary antibody (1:2,000 dilution) was peroxidase-linked anti-rabbit IgG (Amersham Biosciences, Piscataway, NJ), and the immunoreactive material was visualized as chemoluminescence on X-ray film with the enhanced chemiluminescence (ECL) detection kit (Pierce). For electron microscope studies, the original and polymerized Bri peptides were incubated at $1 \mathrm{mg} / \mathrm{ml}$ in phosphatebuffered saline, $\mathrm{pH}$ 7.4. Next, $3 \mu \mathrm{l}$ of sample was put onto a carbon-coated 400 mesh $\mathrm{Cu} / \mathrm{Rh}$ grid (Ted Pella, Inc, Redding, CA) and stained with $1 \%$ uranyl acetate in 
distilled water (Polysciences, Inc, Warrington, PA), as previously published [16]. For secondary structure analysis, aliquots of the original Bri peptide and pBri were reconstituted in $5 \mathrm{mM}$ tris buffer ( $\mathrm{pH}$ 7.0) to obtain a peptide concentration of $100 \mu \mathrm{M}$. Circular dichroism was measured on a Jasco J-720 spectropolarimeter (Easton, MD) equipped with a model CTC-344 circular temperature control system (Neslab Inc, Newington, $\mathrm{NH}$ ).

\section{Immunization of mice}

Animal studies were approved by the New York University School of Medicine Institutional Animal Care and Use Committee and were consistent with the recommendations of the American Veterinary Association. Mice facilities were under a strict $12 \mathrm{~h}$ light/dark cycle. Triple transgenic (3xTg) mice (PS1M146V, tauP301L and APPK670N/M671L) are a model of combined tau- and amyloid-related pathology $[19,20]$. To model vascular amyloid deposition, the well-characterized TgSwDI mouse model was used [21,22]. This model expresses the APPE693Q/D694N (Dutch and Iowa) and APPK670N/ M671L (Swedish) mutations. The pBri peptide was dissolved in sterile saline at $1 \mathrm{mg} / \mathrm{ml}$ and mixed $4: 1$ with aluminum hydroxide (alum) adjuvant (Brenntag Biosector, Denmark). Each mouse received a weekly subcutaneous injection of $100 \mu \mathrm{l}$ of the preparation $(50 \mu \mathrm{g}$ of pBri) for 4 weeks, starting at the age of 3 months, followed by an inoculation a month later and two subsequent bimonthly injections. The last three inoculations used $25 \mu \mathrm{g}$ of pBri per animal and the ratio of saline to alum was changed to 9:1. Both the $3 x \operatorname{Tg}$ and TgSwDI mice were divided into two groups of 14 mice each. There were equal numbers of males and females in each experimental group. For each transgenic line, one group received pBri immunization while the second control group received vehicle injections (alum alone). The mice were subject to behavioral testing at the age of 15 to 16 months.

\section{Sensorimotor and cognitive testing}

Sensorimotor and cognitive testing were done as previously described $[16,20,22]$. Prior to testing, the mice were adapted to the room with lights on for $15 \mathrm{~min}$. The main objective of performing these sensorimotor tasks was to verify that any treatment-related effects observed in the cognitive tasks could not be explained by differences in sensorimotor abilities.

\section{Locomotor activity}

A Hamilton-Kinder Smart-frame Photobeam System was used to make a computerized recording of animal activity over a designated period of time. Exploratory locomotor activity was recorded in a circular open-field activity chamber measuring $70 \mathrm{~cm}$ in diameter. A video camera mounted above the chamber automatically recorded horizontal movements in the open field in each dimension. Total distance was measured in centimeters traveled and is defined as the sum of sequential movement between interruptions of the animal. The duration of the behavior was timed over $15 \mathrm{~min}$. Results were reported based on distance traveled $(\mathrm{cm})$, mean resting time and maximum speed of the animal.

\section{Traverse beam}

This task tests balance and general motor coordination and function integration. Mice were assessed by measuring their ability to traverse a graded narrow wooden beam to reach a goal box. This specifically examines hind limb function. The mice were placed on a $1.1 \mathrm{~cm}$ wide beam, $50.8 \mathrm{~cm}$ long, supported $30 \mathrm{~cm}$ above a padded surface on two identical columns. A shaded goal box was attached at each end of the beam. Mice were placed on the beam in a perpendicular orientation to habituate, and were then monitored for a maximum of $60 \mathrm{sec}$. The number of foot slips each mouse made before falling or reaching the goal box was recorded for each of three successive trials. The average number of foot slips for all three trials was calculated and recorded. Errors are defined as foot slips and were recorded both numerically and using Feeney scores. To prevent injury from falling, a soft foam cushion was always kept underneath the beam. Animals that fell off were placed back in the position they were in prior to the fall.

\section{Rotarod}

Each animal was placed onto a rod (diameter $3.6 \mathrm{~cm}$ ) apparatus to assess differences in motor coordination and balance by measuring fore- and hindlimb motor coordination and balance (Rotarod 7650 accelerating model; Ugo Basile, Biological Research Apparatus, Varese, Italy). This was designed to assess motor behavior without a practice confound. The animals were habituated to the apparatus by receiving training sessions of two trials, which was sufficient to reach a baseline level of performance. The mice were tested a further three times, with increasing speed. During habituation, the rotor rod was set at $1.0 \mathrm{rpm}$, which was gradually increased every $30 \mathrm{sec}$ to a maximum speed of $40.0 \mathrm{rpm}$. The rod was wiped clean with $30 \%$ ethanol solution after each session. A soft foam cushion was placed beneath the apparatus to prevent potential injury from falling. Each animal was tested for three sessions, with each session separated by $15 \mathrm{~min}$. The latency to fall or invert (by clinging) from the top of the rotating barrel was recorded.

\section{Radial arm maze}

Spatial learning was evaluated using an eight-arm radial maze with a water well at the end of each arm, as we 
have previously published $[16,20,22]$, for both TgSwDI and $3 \times \mathrm{Tg}$ mice. For each group of transgenic mice, an age-matched control group of non-transgenic mice $(n=$ 10) were also tested in the radial arm maze. Clear Plexiglas guillotine doors, operated by a remote pulley system, controlled access to the arms from a central area from which the animals entered and exited the apparatus. After 4 days of adaptation to the maze, waterrestricted mice (only given access to water $2 \mathrm{~h}$ per day) were given one training session per day for 10 consecutive days. We use this relatively long adaptation period as we have found that these transgenic ( $\mathrm{Tg}$ ) $\mathrm{AD}$ mice tend to be anxious and will not run the maze well without adaptation $[16,20,22]$. Prior to each day's testing, the mice were adapted to the room with the lights on for $15 \mathrm{~min}$. For each session, all arms were baited with saccharine-flavored water, and the animals were permitted to enter all arms until the eight rewards had been consumed. The number of errors (entries to previously visited arms) and time to complete each session were recorded.

\section{Antibody levels}

Antibody levels were determined in duplicate on 1:100 dilutions of plasma using ELISA as described previously $[16,20,22]$, in which $50 \mu \mathrm{g} /$ plate aggregated $A \beta 1-42$, aggregated $A \beta 1-40, \mathrm{pBri}$ or purified human paired helical filaments (PHF) was coated onto Immulon $2 \mathrm{HB}$ 96-well microtiter wells (Thermo, Waltham, MA). The human PHF was prepared and characterized for purity by Western blotting with PHF1 and electron microscopy, as previously published [16]. The bound antibodies were detected by a horseradish peroxidase-labeled goat anti-mouse IgG (Amersham Biosciences, Piscataway, NJ) or a peroxidase conjugated goat anti-mouse IgM (Sigma; A8786). The color developing substrate was tetramethylbenzidine (TMB) (Pierce, Rockford, IL) and the readings were made at $450 \mathrm{~nm}$.

\section{Histology}

The mice were anesthetized with sodium pentobarbital $(150 \mathrm{mg} / \mathrm{kg}$, intraperitoneally), perfused transaortically with phosphate buffer, and the brains processed as described previously $[16,20,22]$. The right hemisphere was immersion-fixed in periodate-lysine-paraformaldehyde, whereas the left hemisphere was snap-frozen for measurements of $A \beta$ levels in both transgenic lines and phosphorylated tau in the $3 \times \mathrm{xTg}$ mice. Serial coronal sections $(40 \mu \mathrm{m})$ were cut (30 to 40 sections in total), and every fifth section was stained with a mixture of 4G8 and 6E10, which are monoclonal antibodies that recognize $A \beta$ and stain both pre-amyloid and $A \beta$ plaques [23,24]. In 3xTg mice, the degree of tau-related pathology was determined with anti-abnormally phosphorylated tau monoclonal antibodies PHF1 (which recognizes phosphorylated serine in position 396 and 404) [25] and AT8 (which recognizes tau phosphorylated at both serine 202 and threonine 205) [26]; these antibodies were kindly provided by Dr Peter Davies from the Albert Einstein College of Medicine, Bronx, NY.

Glial fibrillary acidic protein (GFAP) is a component of the glial intermediate filaments that forms part of the cytoskeleton and is found predominantly in astrocytes. CD45 is a protein tyrosine phosphatase, commonly used to detect microglial activation at the later stages of plaque development $[27,28]$. Two series of sections were immunostained with anti-GFAP (Dako, Carpinteria, CA) and anti-CD45 (Abd Serotec, Raleigh, NC) antibodies.

Immunostaining was performed as described previously $[16,20,22]$. Briefly, sections were incubated in $6 \mathrm{E} 10 /$ 4G8 each at a 1:1000 dilution in PBS-T for $3 \mathrm{~h}$. A mouseon-mouse immunodetection kit (Vector Laboratories, Burlingame, CA) was used. The sections were incubated first with biotinylated anti-mouse IgG secondary antibody for $1 \mathrm{~h}$ at a 1:2000 dilution and later with the avidin-peroxidase complex for $30 \mathrm{~min}$ at the same dilution. The sections were then reacted in 3,3-diaminobenzidine tetrahydrochloride with nickel ammonium sulfate (Mallinckrodt, Paris, KY) color intensification solution. Immunohistochemistry of 6E10/4G8 immunolabeled tissue sections was quantified with a Bioquant image analysis system (BIOQUANT Image Analysis Corporation, Nashville, TN), and unbiased sampling was used [24]. All procedures were performed by an individual blinded to the experimental conditions of the study.

The cortical area analyzed was dorsomedial from the cingulate cortex and extended ventrolaterally to the rhinal fissure within the right hemisphere. The area of the grid was $800 \times 800 \mu \mathrm{m}^{2}$, and the $\mathrm{A} \beta$ deposit load was measured for 20 cortical frames per mouse $\left(640 \times 480 \mu \mathrm{m}^{2}\right.$ each $)$ chosen randomly. The threshold of the $A \beta$ immunoreactive areas was set so that areas of $<5 \mu \mathrm{m}$ in diameter are not counted. This was done so that small artifactual areas of staining were not counted and the intra-neuronal immunoreactivity was also not counted. With the latter caveat, the $A \beta$ burden was defined as the percentage of the area in the measurement field occupied by the reaction product. GFAP-staining (polyclonal, 1:1000; 3 h, Dako, Denmark) was performed with a primary antibody diluent composed of $0.3 \%$ triton X-100, $0.1 \%$ sodium azide, $0.01 \%$ bacitracin, $1 \%$ bovine serum albumin (BSA) and 10\% normal goat serum in PBS, and a secondary biotinylated goat anti-rabbit antibody (Vector Laboratories, Burlingame, $\mathrm{CA}$ ) reacted for $1 \mathrm{~h}$ at 1:1000 dilution. The analysis of the CD45 immunohistochemistry (rat anti-mouse, 1:500; $3 \mathrm{~h}$, Serotec) was performed like the GFAP-staining except that the secondary antibody was goat anti-rat (Vector Laboratories, Burlingame, CA) diluted 1:1000. 


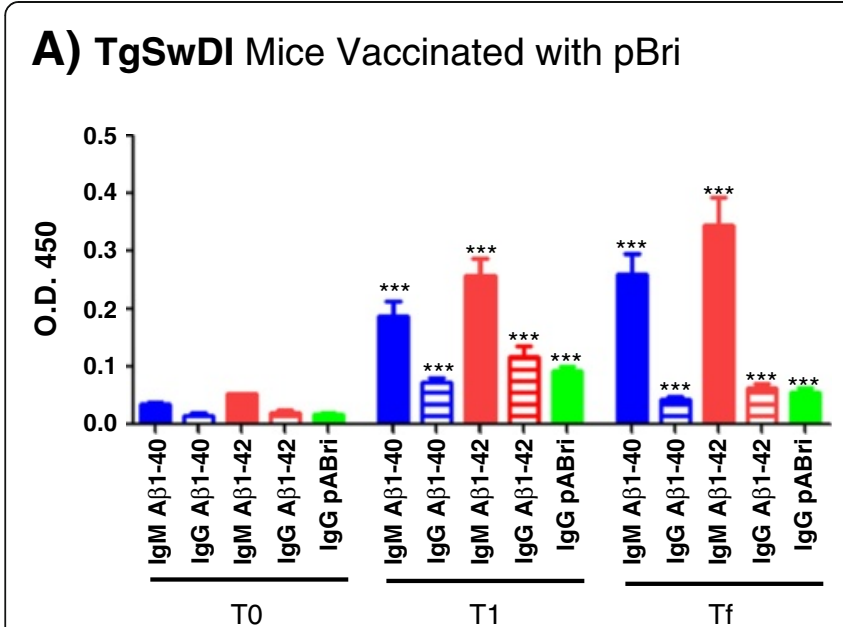

\section{B) 3xTg Mice Vaccinated with pBri}

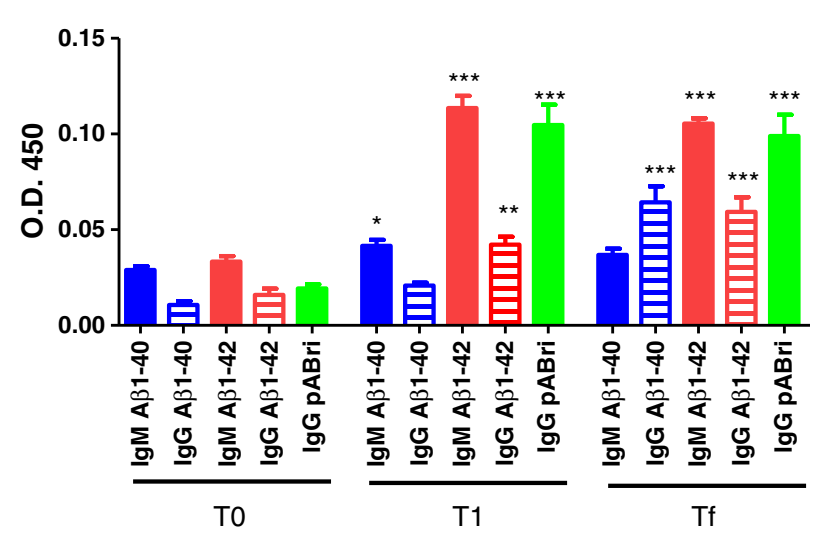

Figure 1 Plasma antibody levels to aggregated $A \beta 40, A \beta 42$ and $p B r i$ in pBri-vaccinated mice. Shown are bar graphs of the $\lg M$ and $\lg G$ antibody levels of (A) TgSwDI and (B) 3xTg and against A $440, A \beta 42$ and pBri at T0 (before vaccination), $T 1$ (after the fourth inoculation) and Tf (at the time of sacrifice). Plasma samples were evaluated at a dilution of $1: 100$ in duplicate. ${ }^{*} P \leq 0.05,{ }^{* *} P \leq 0.01$ and ${ }^{* * *} P \leq 0.001$ by unpaired two-tailed $t$-tests, comparing values at T1 and Tf to T0. Error bars represent mean \pm standard error of the mean). A $\beta$, amyloid $\beta ;$ OD, optical density.

The tau burden was analyzed based on the extent of immunostaining with two anti-tau antibodies, PHF1 and AT8, as previously described [20]. PHF1 was analyzed at 10x magnification in both the hippocampus and cortex. Approximately six sections were analyzed per animal. AT8 was analyzed at $10 \times$ magnification for the hippocampus (AT8 was not analyzed in the cortex as the cortical
AT8 immunolabeling was minimal). Approximately eight cortical sections and six hippocampal sections were analyzed per animal. The rating was based on the number of reactive neuronal bodies and processes. Reactive astrocytosis (GFAP immunoreactivity) was rated on a scale of 0 to 4 . The rating was based on a semiquantitative analysis of the extent of GFAP immunoreactivity (the number of GFAP
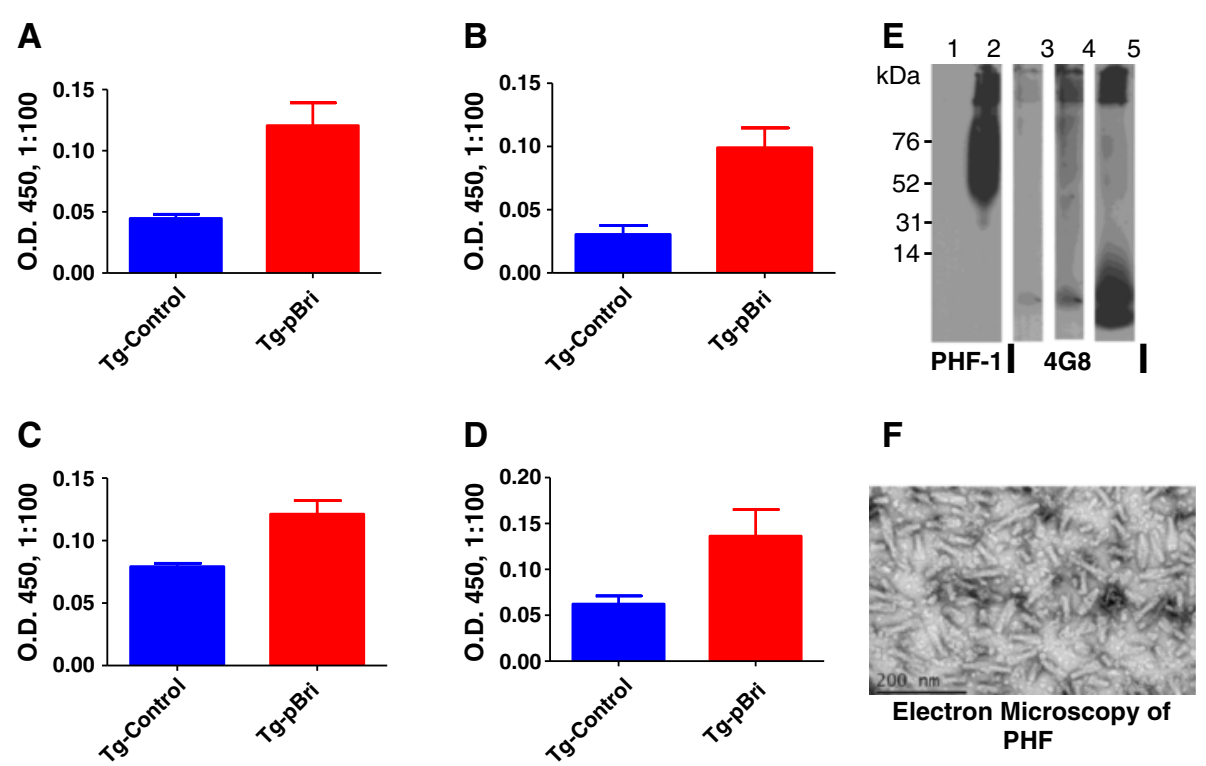

Figure 2 Antibody titers in plasma reactive against purified human paired helical filaments (PHF) at Tf and characterization of the PHF preparation. Titers for the TgSwDI and 3xTg mice were determined against human purified PHF at Tf for both IgM and IgG and were compared to vehicle-inoculated Tg controls. Shown are the titers for TgSwDI IgM (A), $\operatorname{TgS} W D I \lg G$ (B), 3xTg IgM (C) and 3xTg IgG (D). These differences in titer are statistically significant by two-way unpaired $t$-tests $(P=0.0038, P=0.0037, P=0.0057$ and $P=0.04$, respectively). (E) Western blot of the human PHF sample used to seed the ELISA plates in (A) to (D). (F) Electron micrograph of the human PHF sample used, revealing the expected paired helical filaments. OD, optical density; Tg, transgenic. 


\section{A TgSwDI mice}

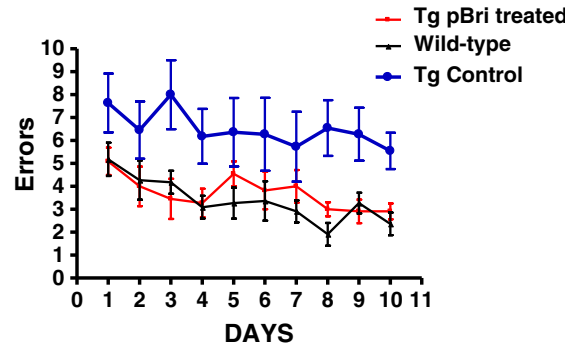

\section{B $3 \times$ Tg mice}

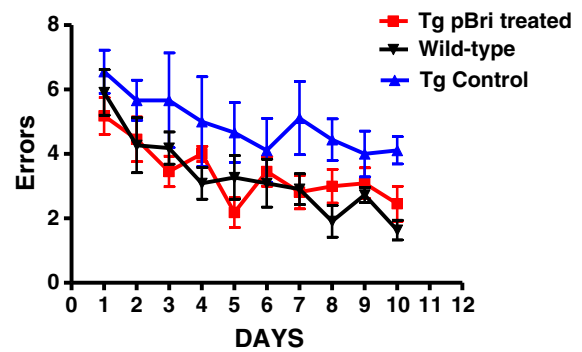

Figure 3 Cognitive testing of TgSwDI and 3xTg mice using a radial arm maze. The number of errors is plotted versus the day of testing. (A) Results for TgSwDI mice. (B) Results for 3xTg mice. There are no differences between the wild-type controls and the pBri-treated TgSwDI mice. There are statistically significant differences between the vehicle control mice and the pBri-treated TgSwDI mice and wild-type controls using two-way ANOVA, and the treatment effect had $P<0.001$. Newman-Keuls post hoc analyses indicate that both the wild-type controls and pBri-vaccinated Tg mice were significantly different from the control Tg mice $(P<0.001)$. There are no differences between the wild-type controls and the pBri-treated 3xTg mice. There are statistically significant differences between the vehicle control mice and the pBri-treated 3xTg mice and wild-type controls using two-way ANOVA, and the treatment effect had $P<0.001$. Newman-Keuls post hoc analyses indicate that both the wild-type controls and pBri-vaccinated Tg mice were significantly different from the control $\operatorname{Tg}$ mice $(P<0.01)$. Tg, transgenic.

immunoreactive cells and complexity of astrocytic branching), as we have previously published [16,20,22]. The assessment of the CD45 immunostained sections was based on a semiquantitative analysis of the extent of microgliosis ( 0 , no microglia; 1 , a few resting microglia; 2, a few ramified and/or phagocytic microglia; 3 , moderate number of ramified/phagocytic microglia; 4 , numerous ramified/phagocytic microglia), as we have previously reported $[16,20,22]$.

Perl's iron staining was performed for the TgSwDI mice on another set of sections to detect cerebral microhemorrhages, as we have previously reported [22]. Sections were stained in a solution containing $5 \%$ potassium ferrocyanide and 10\% hydrochloric acid for $40 \mathrm{~min}$.
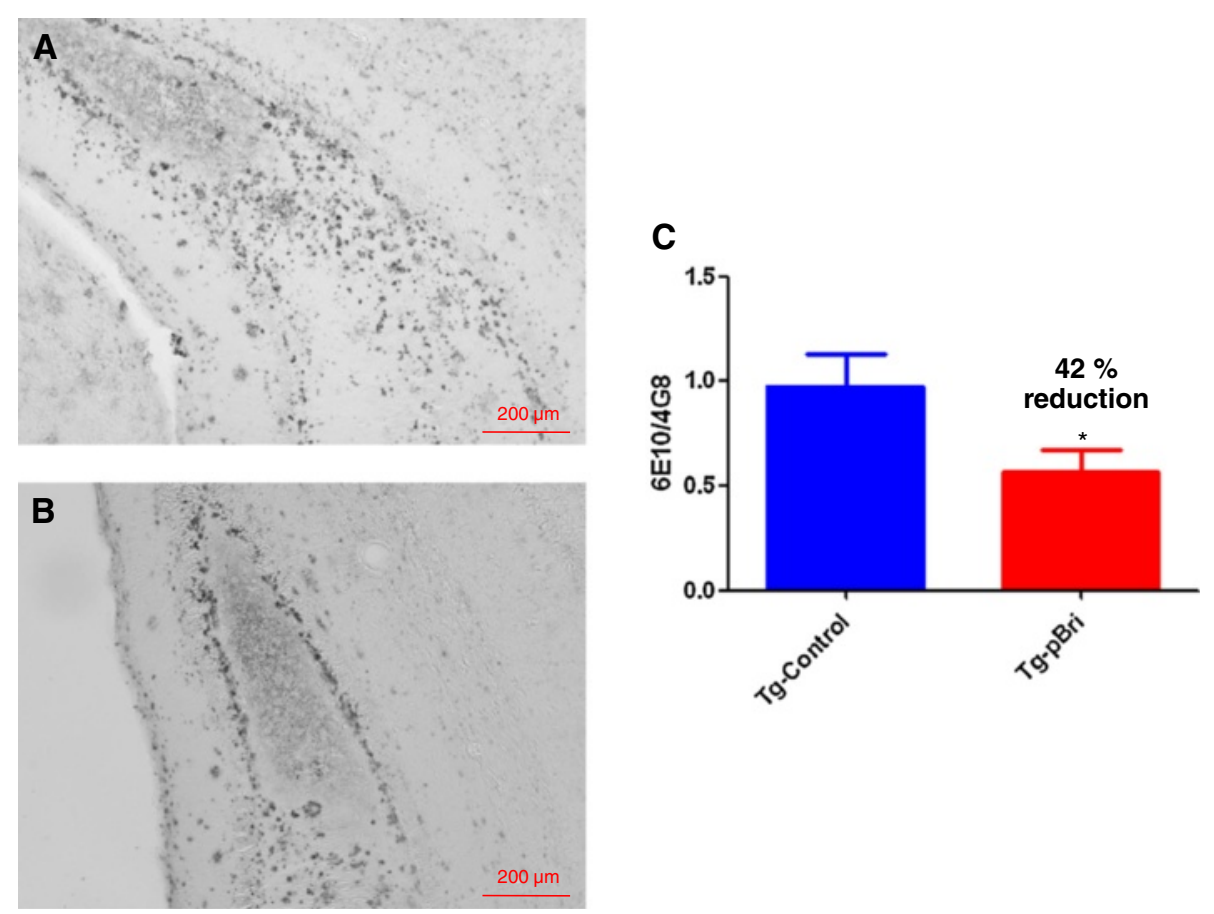

Figure 4 Quantitation of $A \boldsymbol{\beta}$ burden in the hippocampus of TgSwDI mice. Representative brain sections of both (A) vehicle control and (B) pBri-treated Tg mice immunostained with anti-A 3 antibodies 4G8 and 6E10 from the hippocampus. (C) Bar graph of amyloid burden calculated using stereology for the hippocampus of vehicle control and pBri-vaccinated TgSwDI mice. On average there was a $42 \%$ reduction in the areas occupied by $4 \mathrm{G} 8 / 6 \mathrm{E} 10$ immunoreactivity ${ }^{*} P=0.039$ by an unpaired two-tailed $t$-test). Tg, transgenic. 

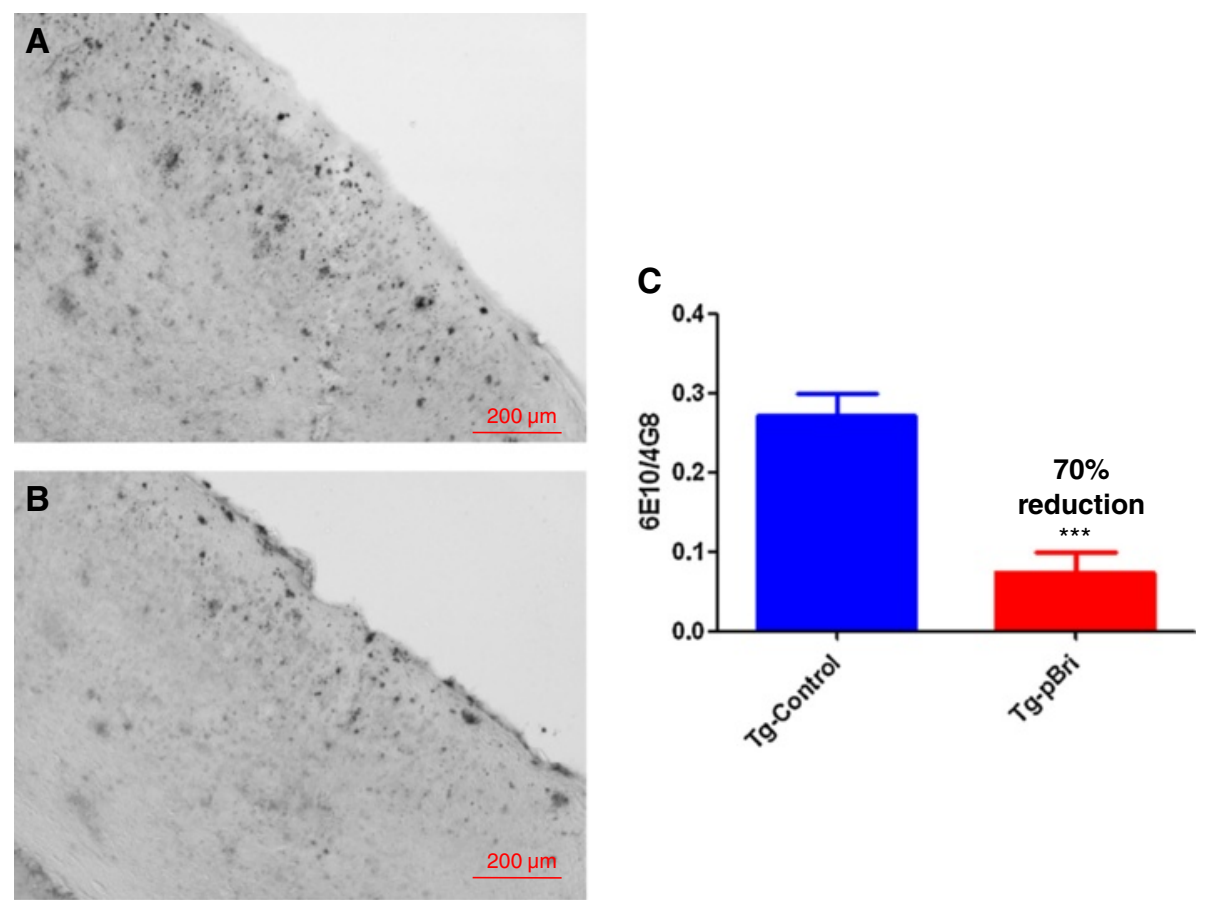

Figure 5 Quantitation of $\mathbf{A} \boldsymbol{\beta}$ burden in the cortex of TgSwDI mice. Representative brain sections of both (A) vehicle control and (B) pBri-treated Tg mice immunostained with anti-A $\beta$ antibodies $4 \mathrm{G} 8$ and $6 \mathrm{E} 10$ from the cortex. (C) Bar graph of amyloid burden calculated using stereology for the cortex of vehicle control and pBri-vaccinated TgSwDI mice. On average there was a 70\% reduction in the areas occupied by 4G8/6E10 immunoreactivity accounting for precipitated amyloid (*** $P=0.0004$ by an unpaired two-tailed $t$-test). Tg, transgenic.
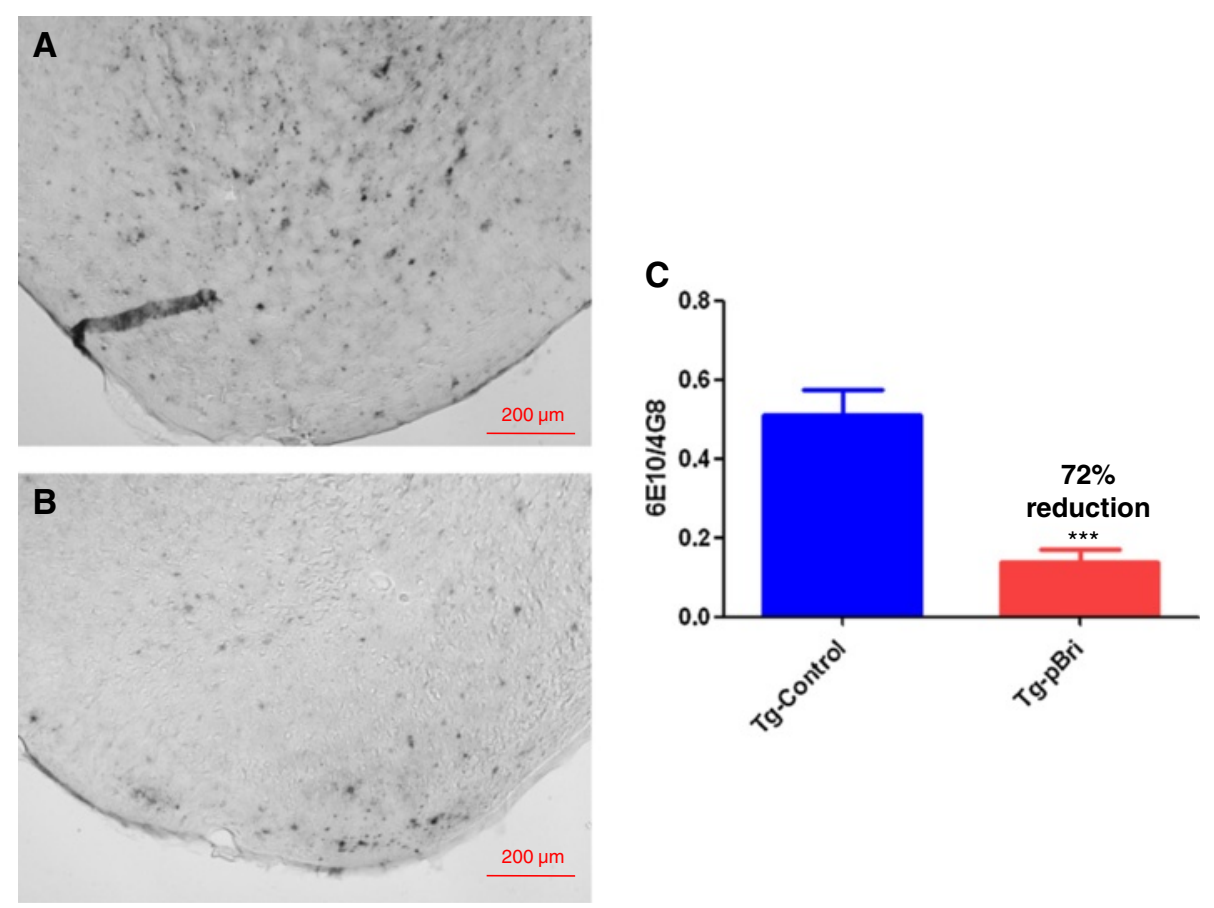

Figure 6 Quantitation of amyloid burden in the amygdala of TgSwDI mice. Representative brain sections of both (A) vehicle control and (B) pBri-treated Tg mice immunostained with anti-A 3 antibodies 4G8 and 6E10 from the amygdala. (C) Bar graph of amyloid burden calculated using stereology for the amygdala of vehicle control and pBri-vaccinated TgSwDI mice. On average there was a $72 \%$ reduction in the areas occupied by 4G8/6E10 immunoreactivity accounting for precipitated amyloid (*** $P<0.0004$ by an unpaired two-tailed $t$-test). Tg, transgenic. 

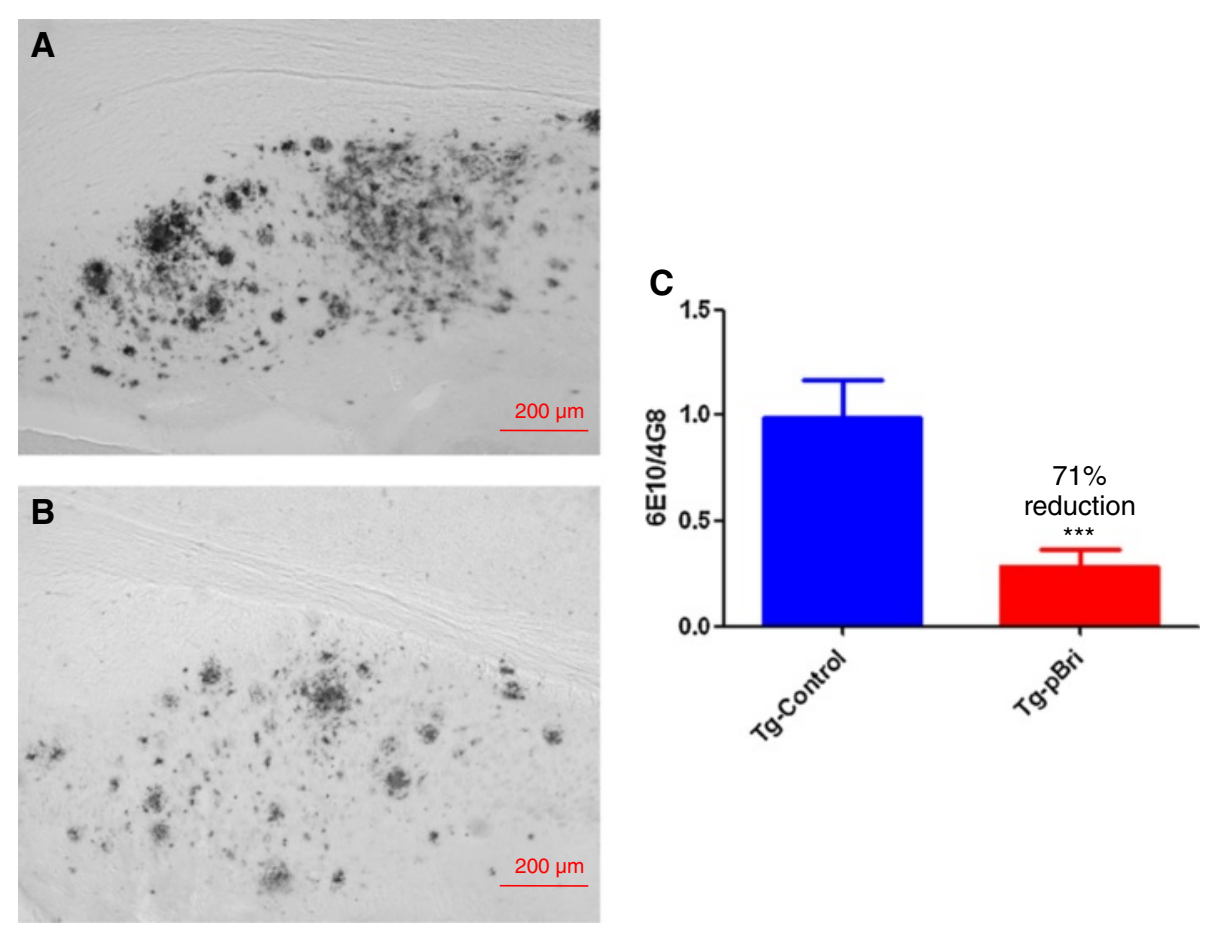

Figure 7 Quantitation of amyloid burden in the hippocampus of 3xTg mice. Representative brain sections of both (A) vehicle control and (B) pBri-treated Tg mice immunostained with anti-A 3 antibodies $4 \mathrm{G} 8$ and $6 \mathrm{E} 10$ from the hippocampus. (C) Bar graph of hippocampus burden calculated using stereology for the hippocampus of vehicle control and pBri-vaccinated 3xTg mice. On average there was a $71 \%$ reduction in the areas occupied by 4G8/6E10 immunoreactivity accounting for precipitated amyloid (*** $P=0.0006$ by an unpaired two-tailed $t$-test). Tg, transgenic.

\section{Tissue homogenization and sandwich ELISA assay for} soluble $A \beta$ levels

A $\beta$ was extracted from brain tissue as described [24] for both TgSwDI and 3xTg mice. Brains were weighed and homogenized $(20 \% \mathrm{w} / \mathrm{v})$ in a homogenization buffer, $20 \mathrm{mM}$ Tris, $250 \mathrm{mM}$ sucrose, $1 \mathrm{mM}$ Ethylenediaminotetraacetic acid disodium salt (EDTA), $1 \mathrm{mM}$ Ethylene glycol tetraacetic acid tetrasodium salt (EGTA) with freshly prepared $100 \mathrm{mM}$ phenylmethylsulfonyl fluoride, $5 \mu \mathrm{g} / \mathrm{ml}$ pepstatin A and a protease inhibitor cocktail (Complete, Roche Diagnostics, Indianapolis, IN). Subsequently, $400 \mu \mathrm{l}$ of the solutions was spun at $100,000 \mathrm{~g}$ for $1 \mathrm{~h}$ at $4^{\circ} \mathrm{C}$,
A) TgSwDI Mice Vaccinated with pBri

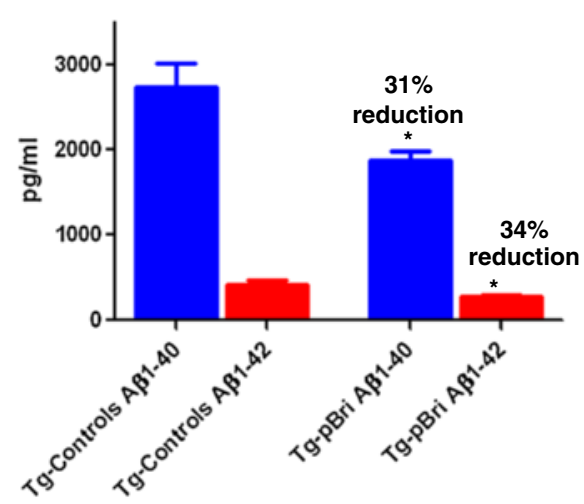

B) $3 \times T$ Mice Vaccinated with pBri

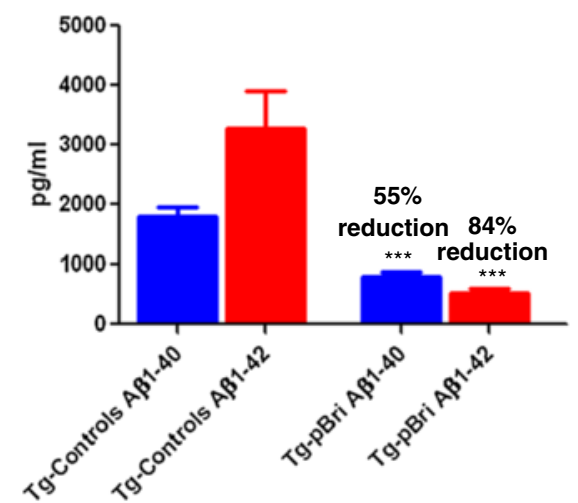

Figure 8 Levels of soluble $\mathbf{A} \boldsymbol{\beta} \mathbf{4 0}$ and $\mathbf{A} \boldsymbol{\beta} \mathbf{4 2}$ in $\mathbf{2 0 \%}$ brain homogenates. (A) TgSwDI treated and Tg control groups show a 31\% and $34 \%$ reduction in the levels of $A \beta 40\left({ }^{*} P=0.02\right)$ and $A \beta 42(* P=0.01)$. (B) There was a $55 \%$ and $84 \%$ reduction in the levels of $A \beta 40(* * * P<0.0001)$ and $\mathrm{A} \beta 42\left({ }^{* * *} P=0.0004\right)$ between $3 \times \mathrm{Tg}$ treated and vehicle control groups, respectively. $P$ values are by unpaired two-tailed $t$-tests. Tg, transgenic. 

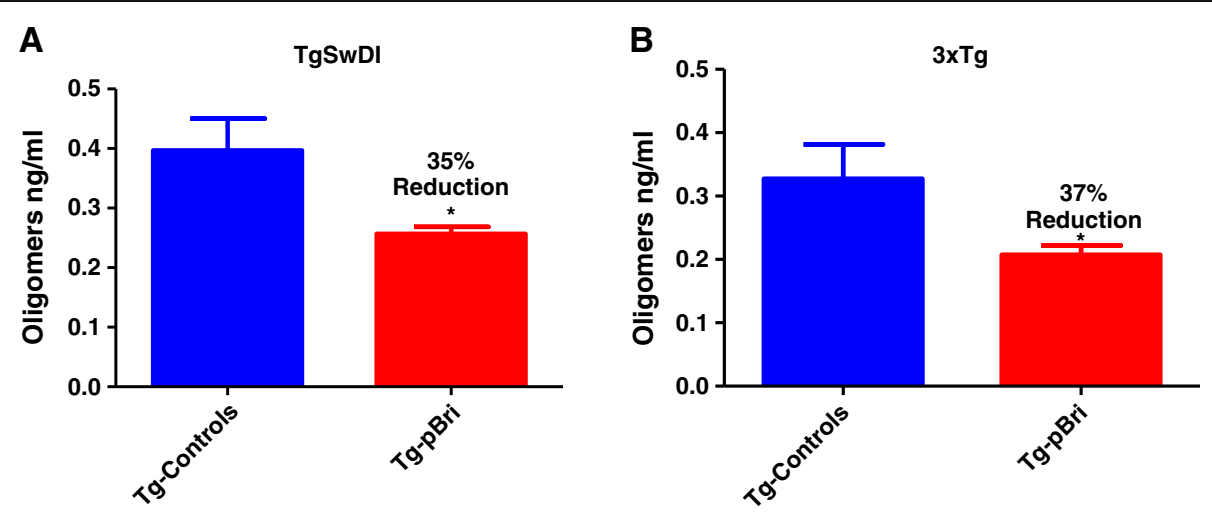

Figure 9 Quantitation of $\mathbf{A} \boldsymbol{\beta}$ oligomers. Oligomer levels in the soluble brain fractions were determined using an ELISA specific to aggregated/ oligomeric $A \beta$. Two-tail unpaired $t$-tests of this ELISA data show a significant reduction of levels of A 3 aggregates/oligomers for the $p B r i-t r e a t e d$ group vs. the vehicle group for both (A) TgSwDI mice (35\% reduction) and (B) $3 x \operatorname{Tg}$ mice (37\% reduction) $\left({ }^{*} P=0.02\right.$ and ${ }^{*} P=0.04$, respectively, by unpaired two-tailed $t$-tests). $\mathrm{Tg}$, transgenic.

aliquoted, flash-frozen on dry ice and stored at $-80^{\circ} \mathrm{C}$ until used for both $A \beta$ and tau measurements in ELISA and Western blots.

The total and soluble $A \beta$ levels were measured using a combination of mouse monoclonal antibody 6E10 (specific to an epitope present on amino acid residues 1 to 16 of $A \beta)$ and two different rabbit polyclonal antibodies specific for $A \beta 40$ (R162) and $A \beta 42$ (R165), in a doubleantibody sandwich ELISA as described previously $[23,24]$. The optical density (OD) was measured at $450 \mathrm{~nm}$. The relation between OD and A $\beta$ peptide concentration was determined by a four-parameter logistic $\log$ function. Non-linear curve fitting was performed with the KinetiCalc program (Biotek Instruments, Inc,
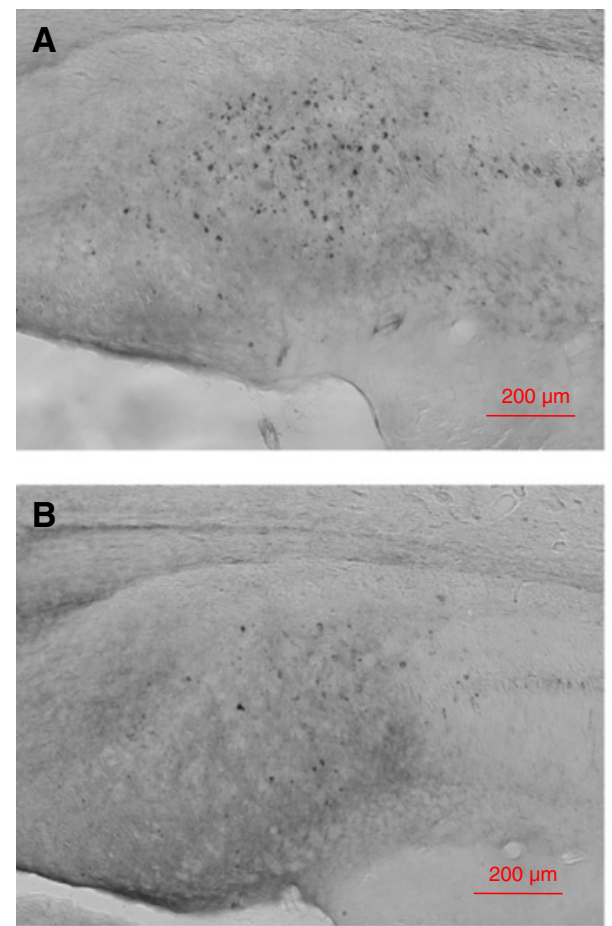

C

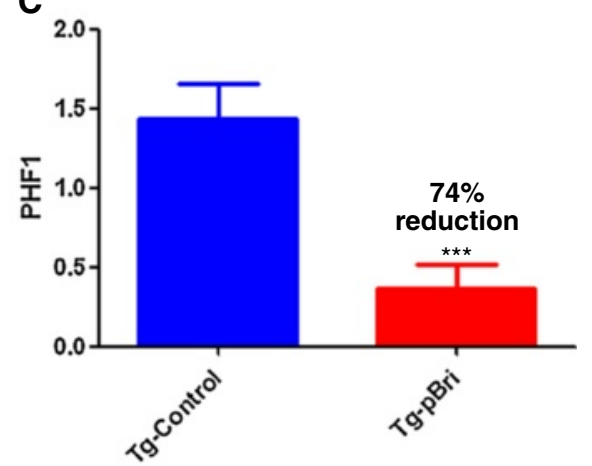

Figure 10 Quantitation of tau burden using PHF1 for the hippocampus of 3xTg mice. The tau burden was analyzed semiquantitatively on a scale of 0 to 4. Representative brain sections of both (A) vehicle control and (B) pBri-treated Tg mice immunostained with PHF1 from the hippocampus. (C) Bar graph of tau semiquantitative analysis for the hippocampus of Tg control and pBri-vaccinated mice. On average there was a $74 \%$ reduction in the areas occupied by PHF1 immunoreactivity accounting for phosphorylated tau (*** $P=0.0005$ by an unpaired two-tailed t-test). $T g$, transgenic. 
Winooski, VT) to convert the OD of plasma to estimated concentrations. The assay was performed by an investigator blinded to group assignment. The levels of $A \beta$ species are presented as micrograms of $A \beta$ per gram of wet brain, taking into account dilution factors introduced by multiple steps throughout the assay (brain homogenization and extraction procedures).

\section{Western blot and Meso Scale Discovery} electrochemiluminescence analysis of phosphorylated tau for 3xTg mice

For Western immunoblot analysis, $20 \% \mathrm{w} / \mathrm{v}$ brain homogenates from the 3xTg mice were centrifuged at $25,000 \mathrm{~g}$ for $10 \mathrm{~min}$ at $4^{\circ} \mathrm{C}$, and the supernatants were transferred to clean tubes and stored as previously described [23,24]. The total protein concentration in the supernatant was determined using the bicinchoninic acid assay (Pierce, Rockford, IL). Samples (40 $\mu \mathrm{g}$ of total protein) were mixed with an equal volume of tricine sample buffer (BioRad, Hercules, CA), electrophoresed on 12.5\% SDS-tris-tricine polyacrylamide gels under non-reducing conditions and transferred to nitrocellulose membranes. To assess whether there was equal protein loading in each lane, the membranes were stained with reversible $0.1 \%$ Fast Green FCF (Fisher Scientific, USA) in 25\% methanol destained in 25\% methanol and transferred to distilled water. The blots were then blocked with 5\% non-fat dry milk in $50 \mathrm{mM}$ tris buffer saline- $0.1 \%$ Tween 20 (TBS-T), $\mathrm{pH} 8.3$, for $2 \mathrm{~h}$ at room temperature, then incubated with PHF1 diluted 1:500 in TBS-T, $0.1 \%$ BSA for $2 \mathrm{~h}$ at room temperature. Bound antibodies were detected after $1 \mathrm{~h}$ incubation with horseradish peroxidase-conjugated goat anti-mouse IgG 1:8000 (Pierce, Rockford, IL) and the ECL detection system (Pierce, Rockford, IL). The specificity of the PHF1 band was confirmed by Western blots using homogenates of non-transgenic mouse brains. Only the bands detected by PHF1 in 3xTg transgenic mouse homogenates and not in the non-transgenic mouse homogenates were quantitated. Densitometric analysis of the PHF1 specific bands was performed with the NIH Image J software version 1.34.

The same $20 \%$ brain homogenates containing only soluble forms of tau were centrifuged at $100,000 \mathrm{~g}$. Total tau and phosphorylated tau (Thr231) were quantified using a Meso Scale Discovery (MSD) (Rockville, MD) system that utilizes electrochemiluminescence analysis. The multiarray phospho (Thr231) tau assay kit, which measures both total human tau and phosphorylated Thr231 tau, was used with the MesoQuickPlex SQ 120 system, following the manufacturer's instructions. In brief, samples were diluted 1:125 with the provided standard diluent buffer and $100 \mu \mathrm{l}$ aliquots were seeded in each well. The plates were incubated for $2 \mathrm{~h}$ at room temperature, then washed four

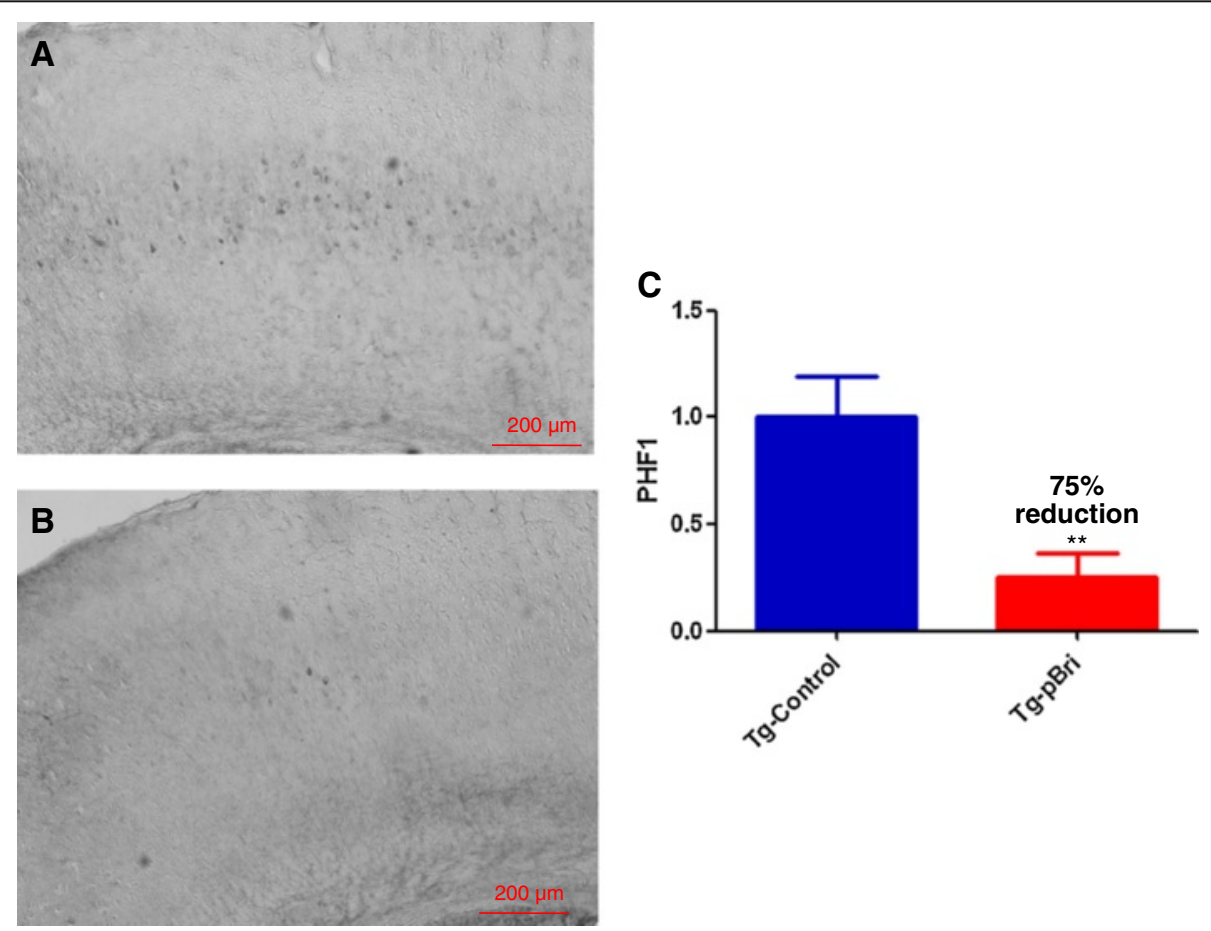

Figure 11 Quantitation of tau burden using PHF1 for the cortex of 3xTg mice. The tau burden was analyzed semiquantitatively on a scale of 0 to 4. Representative brain sections of both (A) vehicle control and (B) pBri-treated Tg mice immunostained with PHF1 from the cortex. (C) Bar graph of tau semiquantitative analysis for the cortex of Tg control and pBri-vaccinated mice. On average there was a $75 \%$ reduction in the areas occupied by PHF1 immunoreactivity accounting for phosphorylated tau (** $P=0.0017$ by an unpaired two-tailed $t$-test). $T$, transgenic. 
times for $25 \mathrm{sec}$ each, before the Hu Aggregated $\mathrm{A} \beta$ biotin conjugate was added and incubated for $1 \mathrm{~h}$. The plates were again washed four times and the Streptavidin-HRP working solutions was added. The plates were covered to block the light and incubated for $25 \mathrm{~min}$ before the reaction was stopped with the stop solution. The plates were read on the MSD system at $450 \mathrm{~nm}$. All data were recorded and calculations made using the software provided with the MSD system.

\section{Quantitation of aggregated/oligomeric $A \beta$}

Aggregated/oligomeric $A \beta$ levels were determined using the Human Aggregated A $\beta$ ELISA kit (Invitrogen, Camarillo, $\mathrm{CA})$, following the manufacturer's instructions. In brief, the levels of aggregated/oligomeric $A \beta$ in each sample were measured against a standard containing aggregated $A \beta$. Next $20 \% \mathrm{w} / \mathrm{v}$ brain homogenates were thawed, diluted 1:4 with the diluents buffer and applied to the ELISA plates. The samples were then incubated for $2 \mathrm{~h}$ at room temperature allowing the $\mathrm{N}$-terminal portion of the $\mathrm{A} \beta$ to bind the pre-coated capture monoclonal antibody, followed by extensive washing and incubation for $1 \mathrm{~h}$ at room temperature with biotin conjugated detection antibodies (same as the capture antibody), which binds only to the immobilized aggregated $A \beta$. After removal of excess antibody, horseradish peroxidase-labelled streptavidin was added. The sample was incubated for $30 \mathrm{~min}$, followed by washing and TMB substrate incubation to produce color. The intensity of this colored product is directly proportional to the concentration of aggregated/oligomeric $A \beta$ in the sample. The standards produced a linear curve and the best-fit lines determined by linear regression were used to calculate aggregated $A \beta$ concentrations in the samples.

\section{Statistical analysis}

Data from the accelerating rotor rod and locomotor test were analyzed using two-tail, Student's $t$-tests. The data collected from the radial arm maze test was analyzed using two-way ANOVA, and also by one-way ANOVA followed by Newman-Keuls post hoc tests. Differences in total amyloid burden, levels of extracted $A \beta$, levels of $A \beta$ aggregates/oligomers, tau burden, astrogliosis and microgliosis between the two groups were analyzed using two-tailed $t$-tests. All statistical tests were performed using Prism 6.0 (Graphpad, San Diego, CA).

\section{Results}

Antibody titers for $A \beta 40, A \beta 42, p B r i$ and human purified PHF For both the TgSwDI strain (Figure 1A) and the $3 \times \mathrm{Tg}$ strain (Figure 1B), pBri-vaccinated mice showed significant
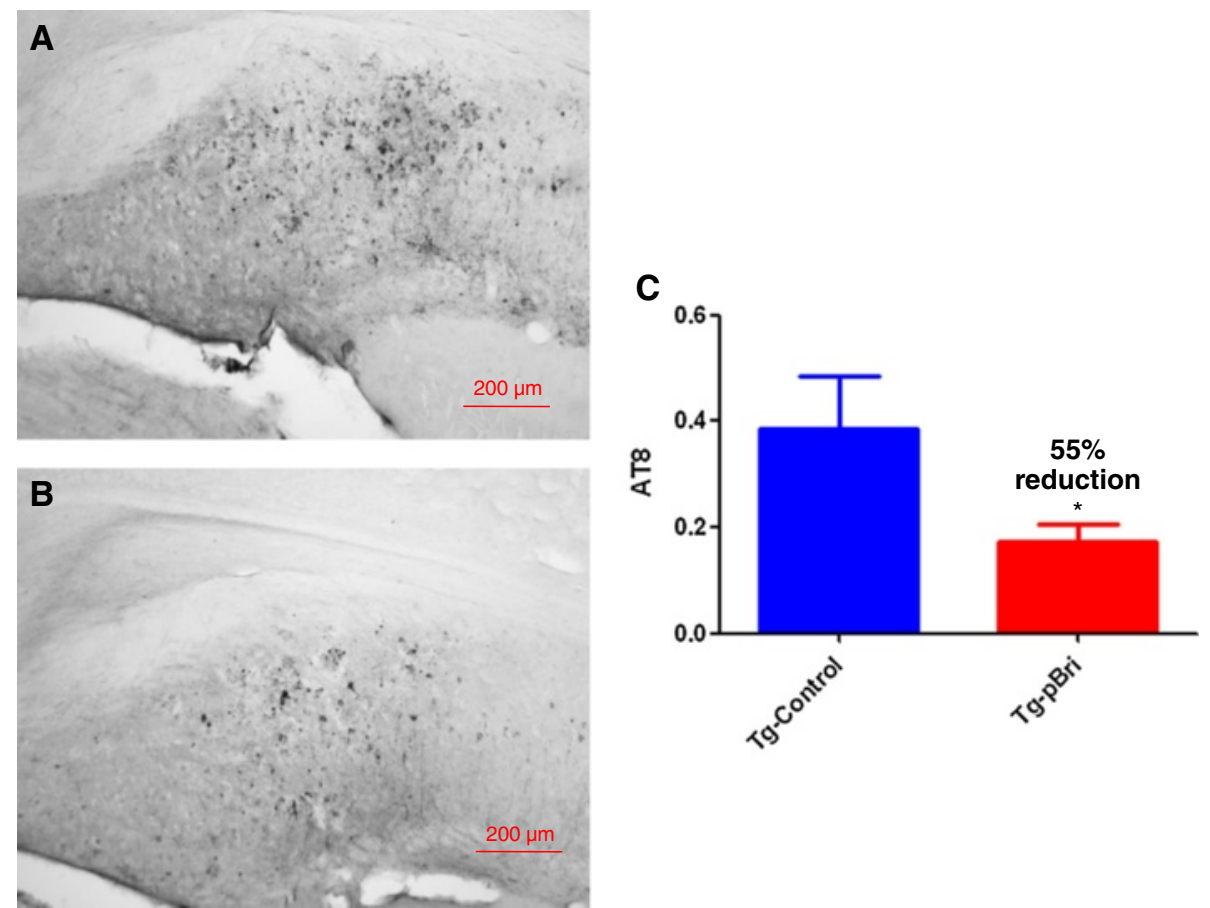

Figure 12 Quantitation of tau burden using AT8 for the hippocampus of 3xTg mice. The tau burden was analyzed semiquantitatively on a scale of 0 to 4 . Representative brain sections of both (A) vehicle control and (B) pBri-treated Tg mice immunostained with AT8 from the hippocampus. (C) Bar graph of tau semiquantitative analysis for the hippocampus of Tg control and pBri-vaccinated mice. On average there was a 55\% reduction in the areas occupied by AT8 immunoreactivity accounting for phosphorylated tau ( ${ }^{*} P=0.03$ by an unpaired two-tailed $t$-test). Tg, transgenic. 
IgG and IgM titers at T1 (after the fourth inoculation) and Tf (at the time of sacrifice) against aggregated $\mathrm{A} \beta 40$, aggregated $\mathrm{A} \beta 42$ and polymerized Bri, compared to equivalent T0 titers (prior to vaccination) by two-tailed unpaired $t$-tests. In the control groups for both TgSwDI and 3xTg strains, as expected, there were no significant differences in $\mathrm{T} 1$ and Tf titers against $\mathrm{A} \beta 40, \mathrm{~A} \beta 42$ and $\mathrm{pBri}$ versus T0, with OD values all being $\leq 0.03$ (data not shown).

Titers for the TgSwDI and 3xTg mice were determined against human purified PHF at Tf for both IgG and IgM and were compared to titers for vehicle-inoculated Tg controls at Tf: TgSwDI IgM (Figure 2A), TgSwDI IgG (Figure 2B), 3xTg IgM (Figure 2C) and 3xTg IgG (Figure 2D). These differences in titer are statistically significant by two-way unpaired $t$-tests $(P=0.0038$, $P=0.0037, P=0.0057$ and $P=0.04$, respectively). Char- acterization of the PHF preparation used for the Western blot and electron microscopy is shown in Figure 2E and F, respectively.

Figure 2E shows a Western blot of the human PHF sample that was used to seed the ELISA plates shown in Figure $2 \mathrm{~A}$ to $\mathrm{D}$. For the Western blot, A $\beta 1-42(2 \mu \mathrm{g})$ was loaded into lane 1 and sonicated human PHF $(5 \mu \mathrm{g})$ was loaded into lane 2. The membrane of lanes 1 and 2 was developed with PHF1 monoclonal antibodies at a dilution of 1:2000. The film was exposed for $60 \mathrm{sec}$. No crossreactivity of the PHF1 antibody with $A \beta$ species can be seen in lane 1. The human PHF preparation consisted of species varying from $50 \mathrm{kDa}$ to more than $200 \mathrm{kDa}$, plus aggregates of higher molecular weight seen at the top of the gel, as identified by PHF1 in lane 2. Then $5 \mu \mathrm{g}$ of the same PHF sample were loaded into lanes 3 and 4 and
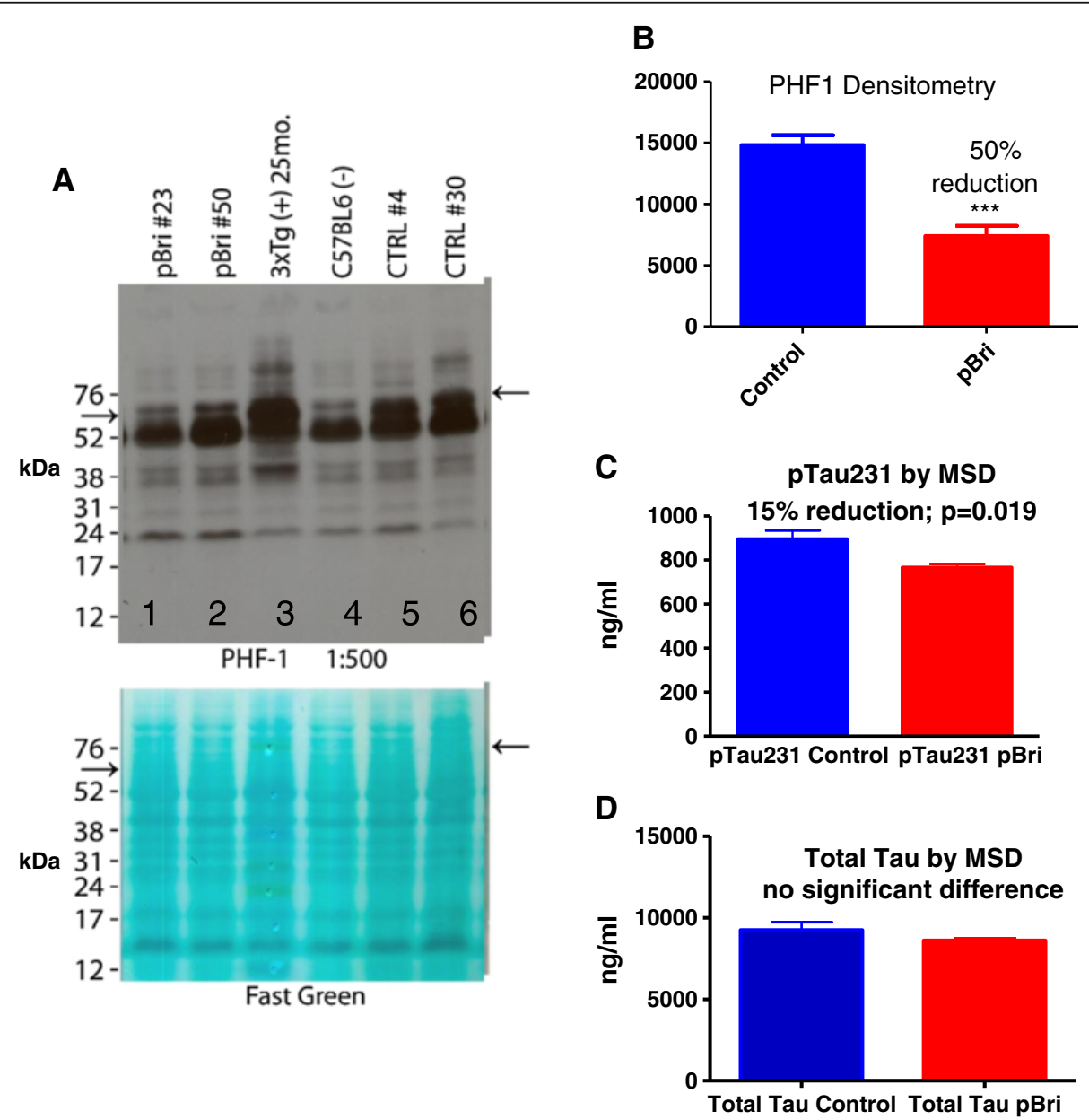

Figure 13 Quantitation of phosphorylated tau in the soluble brain homogenate by Western blot using PHF1 for 3xTg mice.

(A) Upper: Western blot using PHF1. Lower: Membrane stained with Fast Green before being probed with PHF1, shown to illustrate that there was an equal protein load in each of the lanes. (B) Densitometric quantitation of the specific, approximately 60 kDa, PHF1 immunoreactive band, with a $50 \%$ reduction for the pBri-treated $3 \times \operatorname{Tg}$ mice $(P<0.0001$ by an unpaired two-tailed $t$-test). (C) Quantitation of phosphorylated tau (Thr231) and (D) quantitation of total tau using a Meso Scale Discovery (MSD) system that utilizes electrochemiluminescence analysis. There is a significant reduction of phosphorylated tau (Thr231; $P=0.019$ by two-tailed $t$-test) of $15 \%$. There is no significant difference in total tau when comparing pBri-immunized and control 3xTg mice. MSD, Meso Scale Discovery. 
detected by anti-A $\beta$ 4G8 monoclonal antibodies at 1:8000. The membrane shown in lane 3 was exposed for $60 \mathrm{sec}$, the same duration as the membrane shown in lanes 1 and 2 . A very faint band can be seen corresponding to dimeric $\mathrm{A} \beta$, as a minor $(<1 \%)$ contaminant of the PHF preparation. The membrane shown in lane 4 was loaded with the same PHF as in lane 3 but was exposed for 300 sec to reveal the $A \beta$ species present better. In lane 5, aggregated $A \beta 1-42$ $(2 \mu \mathrm{g})$ was run and the membrane was detected by $4 \mathrm{G} 8$; the film was exposed for $10 \mathrm{sec}$ and shows a monomer band as well as higher molecular weight oligomers. The same PHF sample as run in lanes 2 to 4 was used to coat the ELISA plates that were used in Figures $2 \mathrm{~A}$ to $\mathrm{D}$ at $50 \mathrm{ng} /$ well. The amount of $A \beta$ in the PHF samples run in lanes 2 to 4 was estimated to be approximately $100 \mathrm{pg}$. This could not be a factor in the ELISA plate reactions shown in Figures $2 \mathrm{~A}$ to $\mathrm{D}$, since in the ELISA reactions against $A \beta$ peptides shown in Figure 1, no coating below $10 \mathrm{ng} /$ well of $A \beta$ gave results above background. An electron micrograph of the human PHF sample used revealed the expected paired helical filaments (Figure 2F).

\section{Sensorimotor and cognitive testing}

To verify that cognitive testing was not confounded by differences in sensorimotor abilities in the pBri-vaccinated versus control mice, sensorimotor testing was conducted first in both transgenic lines. There were no significant differences between the groups in locomotor activity in terms of distance traveled, maximum speed, mean velocity and rest time for TgSwDI mice (data not shown) or for $3 x T g$ mice (data not shown). Traverse beam testing and rotarod testing also did not reveal any differences between transgenic controls versus treated transgenic mice for both the TgSwDI and 3xTg lines (data not shown).

There were statistically significant differences in the results of the radial arm maze cognitive testing between the untreated control $\mathrm{Tg}$ mice versus the treated $\mathrm{Tg}$ mice and wild-type controls for TgSwDI mice (Figure $3 \mathrm{~A}$ ) and $3 \times \mathrm{Tg}$ mice (Figure 3B). For TgSwDI mice (Figure 3A) using two-way ANOVA, the treatment effect had $P<0.001$ and the day effect was not significant. Post hoc Newman-Keuls testing indicated that both the wild-type controls and treated $\mathrm{Tg}$ mice were significantly different from the control Tg mice $(P<0.001)$. There was no difference between the wild-type controls and the treated $\mathrm{Tg}$ mice.

For 3xTg mice (Figure 3B) using two-way ANOVA the treatment effect had $P<0.001$ and the day effect had $P<0.001$. Post hoc Newman-Keuls testing indicated that both the wild-type controls and treated $\mathrm{Tg}$ mice were significantly different from the control $\mathrm{Tg}$ mice
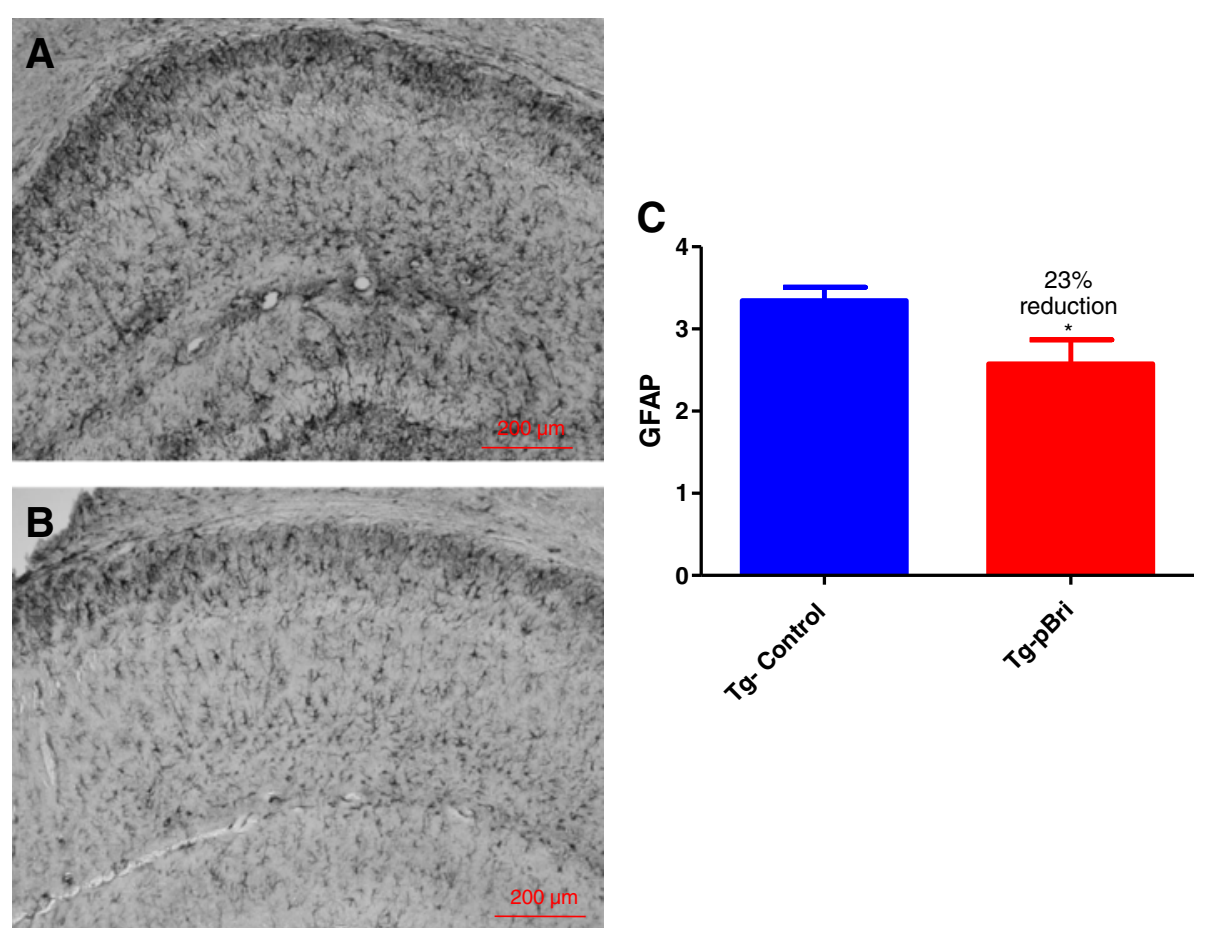

Figure 14 Quantitation of astrocytosis in the hippocampus of TgSwDI mice. Reactive astrocytosis was analyzed semiquantitatively on a scale of 0 to 4. Representative brain sections of both (A) vehicle control and (B) pBri-treated Tg mice immunostained with GFAP from the hippocampus. (C) Bar graph of astrocyte semiquantitative analysis in the hippocampus for vehicle control and pBri-vaccinated mice. On average there was a $23 \%$ reduction in the areas occupied by GFAP immunoreactivity accounting for astrocytosis $\left({ }^{*} P=0.03\right.$ by an unpaired two-tailed t-test). GFAP, glial fibrillary acidic protein; Tg, transgenic. 
$(P<0.01)$. There was no difference between the wildtype controls and the treated $\mathrm{Tg}$ mice.

\section{Amyloid quantitation by stereology and biochemical analysis}

There were significant reductions in the amyloid burden (percentage area occupied by 4G8/6E10 immunoreactivity) for the treated TgSwDI mice in the hippocampus (42\% reduction, Figure 4$)$, the cortex ( $70 \%$ reduction, Figure 5) and the amygdala ( $72 \%$ reduction, Figure 6) with $P=0.039, P=0.0004$ and $P<0.0004$, respectively. Each of the three figures shows a representative section from a control transgenic mouse, a representative section from a pBri-treated transgenic mouse and a histogram of the amyloid burden (scale bar is $200 \mu \mathrm{m}$ ). The amyloid burdens we calculated for these $\mathrm{Tg}$ mice are similar to what we and others have previously reported [22,23,29-32]; however, the burdens are less than in some other reports [33]. This variability is likely related to differing experimental procedures between laboratories.

There were significant reductions in the amyloid burden in the hippocampus of treated $3 x \mathrm{Tg}$ mice $(71 \%$ reduction, $P=0.0006$, Figure 7). Figure 7A is a representation section from a control transgenic mouse. Figure $7 \mathrm{~B}$ is a representative section from a pBri-treated transgenic mouse and
Figure $7 \mathrm{C}$ is a histogram of the amyloid burden (scale bar is $200 \mu \mathrm{m}$ ). The amyloid burden in the cortex of these $3 x \mathrm{Tg}$ mice was too low for meaningful quantitative studies.

Significant reductions in the biochemically extracted $A \beta 40$ and $A \beta 42$ levels were also noted for both the TgSwDI and 3xTg mice in the soluble fraction of $20 \%$ brain homogenates (Figure 8). For the TgSwDI mice, $\mathrm{A} \beta 40$ and $\mathrm{A} \beta 42$ levels were reduced by $31 \%$ and $34 \%$, respectively $(P=0.02$ and $P=0.01$, respectively, by unpaired two-tailed $t$-tests) (Figure $8 \mathrm{~A}$ ). For the $3 \times \mathrm{TTg}$ mice $A \beta 40$ and $A \beta 42$ levels were reduced by $55 \%$ and $84 \%$, respectively $(P<0.0001$ and $P=0.0004$, respectively $)$ (Figure 8B).

\section{Quantitation of $A \beta$ oligomers}

Soluble oligomeric/aggregated $\mathrm{A} \beta$ ligands (also known as ADDLs) may account for memory loss and $A D$ neuropathology, thus they are a significant therapeutic target [34]. We measured oligomers in the soluble brain fractions using an ELISA specific to aggregated/ oligomeric $A \beta$, similar to prior studies by us and others $[20,35,36]$. Two-tail unpaired $t$-tests of this ELISA showed a significant reduction of levels of $A \beta$ aggregates/oligomers for the pBri-treated group vs. the
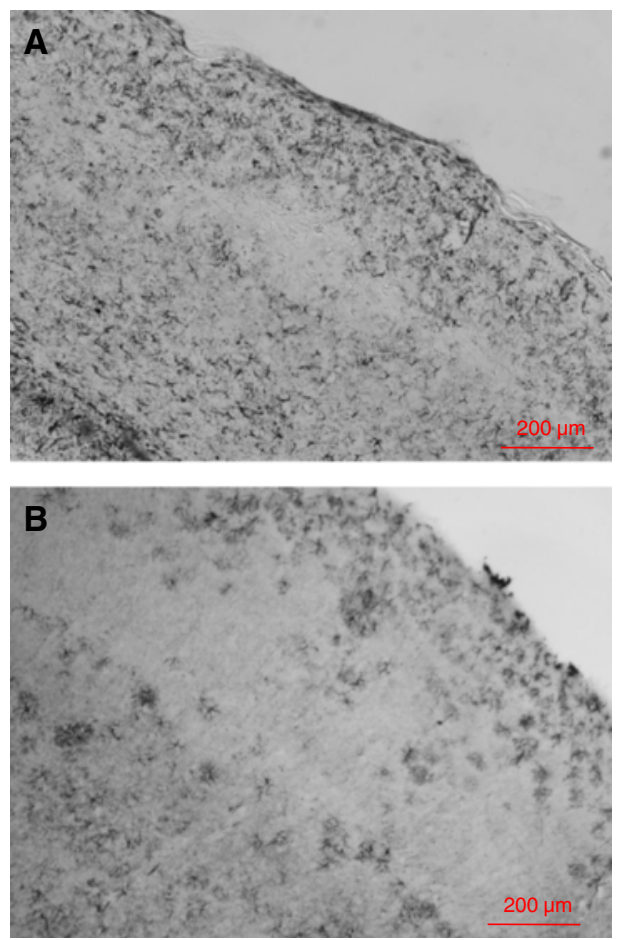

C

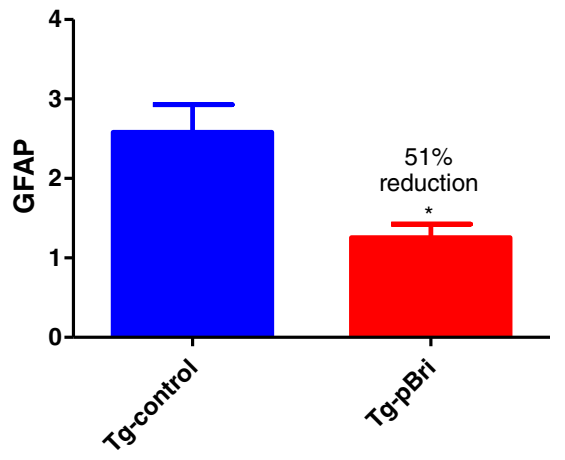

Figure 15 Quantitation of astrocytosis in the cortex of TgSwDI mice. Reactive astrocytosis was analyzed semiquantitatively on a scale of 0 to 4. Representative brain sections of both (A) vehicle control and (B) pBri-treated Tg mice immunostained with GFAP from the cortex. (C) Bar graph of astrocyte semiquantitative analysis for the cortex of vehicle control and pBri-vaccinated mice. On average there was a 51\% reduction in the areas occupied by GFAP immunoreactivity accounting for astrocytosis ( $* P=0.015$ by an unpaired two-tailed $t$-test). GFAP, glial fibrillary acidic protein; $T g$, transgenic. 
vehicle group for both TgSwDI mice (Figure 9A, 35\% reduction) and 3xTg mice (Figure 9B, 37\% reduction) $\left({ }^{*} P=0.02\right.$ and ${ }^{*} P=0.04$, respectively, by unpaired twotailed $t$-tests).

\section{Quantification of tau burden in 3xTg mice}

To determine the treatment effect of pBri immunomodulation on tau pathology for $3 x \operatorname{Tg}$ mice, we used a semiquantitative analysis to quantify the tau burden in the region of the hippocampus and cortex for the serial sections as we have previously published [20]. Two anti-tau antibodies, AT8 (which recognizes tau phosphorylated at both serine 202 and threonine 205) and PHF1 (which recognizes phospho-tau epitopes serine 396 and 404), were used. AT8 immunoreactivity was observed mainly in the hippocampus of our 3xTg mice, while PHF1 immunoreactivity was observed in both the hippocampus and cortex. PHF1 immunoreactivity was reduced by $74 \%$ and $75 \%$ in the hippocampus (Figure 10) and cortex (Figure 11) of pBri-vaccinated mice, respectively $(P=0.0005$ and $P=0.0017$ by twotailed $t$-tests, respectively). AT8 immunoreactivity was reduced by $55 \%$ in the hippocampus of pBri-treated mice $(P=0.03)$ (Figure 12).
Quantitation of phosphorylated tau in the soluble brain homogenate by Western blot using PHF1 and Meso Scale Discovery analysis of total tau and phosphorylated tau (Thr231)

A PHF1-specific band was noted at approximately $60 \mathrm{kDa}$ by Western blotting (see arrows in Figure 13A). This band has been previously reported in 3xTg mice using PHF1; other bands were also detected but are not specific for phosphorylated tau [37]. Densitometric quantitation of this band showed there was a $50 \%$ reduction for the pBritreated 3xTg mice (see Figure 13B, $P<0.0001$ by an unpaired two-tailed $t$-test). Figure 13A shows representative samples from two pBri-treated mice in lanes 1 and 2 . A sample from a 25-month-old 3xTg mouse (with more extensive tau pathology) was run as a positive control in lane 3. In lane 4, a sample from an age-matched wild-type mouse was run as a negative control, highlighting that the other bands seen with PHF1 are not specific for phosphorylated tau. Representative samples from two vehicletreated 3xTg control mice were run in lanes 5 and 6 . A strong band can be seen at approximately $60 \mathrm{kDa}$ in lanes 5 and 6 (see arrow). This band has about the same intensity as the equivalent band for the positive control, the 25month-old 3xTg mouse sample in lane 3, and is much
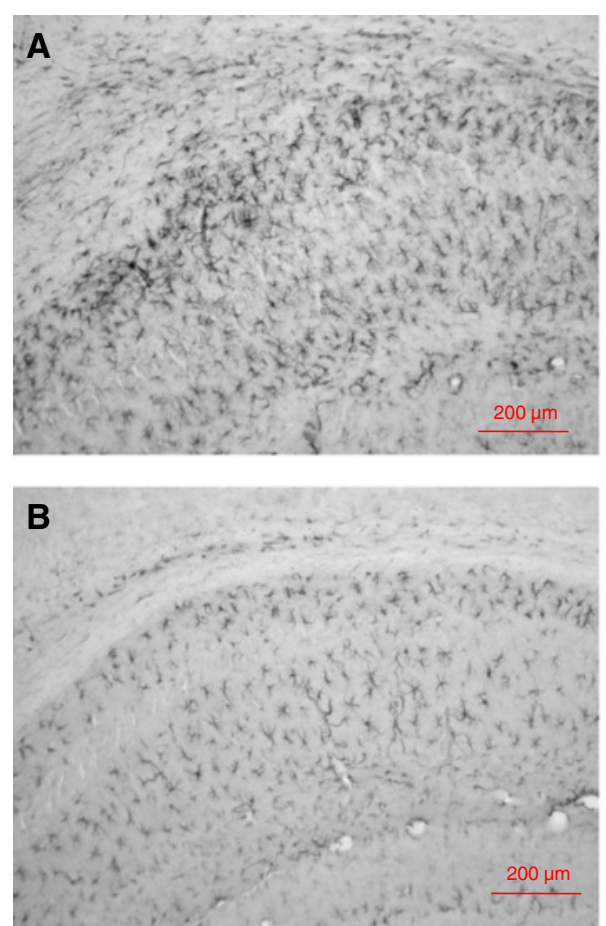

C

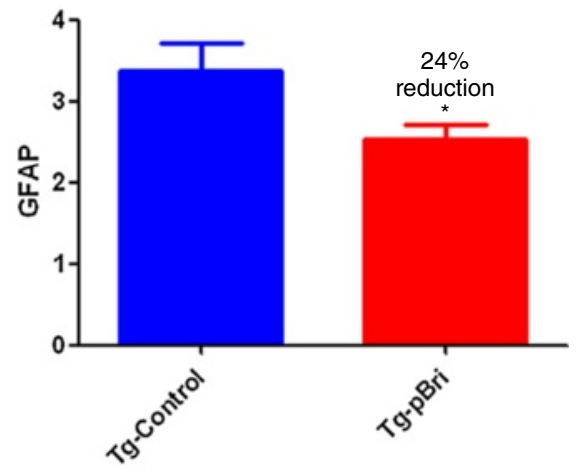

Figure 16 Quantitation of astrocytosis in the hippocampus of 3xTg mice. Reactive astrocytosis was analyzed semiquantitatively on a scale of 0 to 4. Representative brain sections of both (A) vehicle control and (B) pBri-treated Tg mice immunostained with GFAP from the hippocampus. (C) Bar graph of astrocyte semiquantitative analysis for the hippocampus of vehicle control and pBri-vaccinated mice. On average there was a $24 \%$ reduction in the areas occupied by GFAP immunoreactivity accounting for astrocytosis ( $P=0.03$ by an unpaired two-tailed $t$-test). GFAP, glial fibrillary acidic protein; Tg, transgenic. 
stronger than the equivalent bands for the pBri-treated mice in lanes 1 and 2. The membrane stained with Fast Green shows there was an equal protein load in each of the lanes.

MSD analysis of phosphorylated tau (Thr231) showed a significant reduction $(P=0.019)$ of $15 \%$ (Figure 13C), while the analysis of total tau showed there was no significant difference between control and pBri-treated 3xTg mice (Figure 13D).

\section{Assessment of astrocytosis and microglial activation}

GFAP immunoreactivity in the hippocampus (Figure 14) and cortex (Figure 15) for pBri-treated TgSwDI mice versus control $\mathrm{Tg}$ mice was reduced by $23 \%$ and $51 \%$, respectively $(P=0.03$ and $P=0.015$ by two-tailed unpaired $t$-tests). GFAP immunoreactivity in the hippocampus (Figure 16) and cortex (Figure 17) for pBri-treated 3xTg mice versus control $\mathrm{Tg}$ mice was reduced significantly by $24 \%$ and $91 \%$, respectively $(P=0.03$ and $P=0.0001$ by two-tailed unpaired $t$-tests).

The assessment of the microglial marker CD45 was based on semiquantitative analyses of the extent of microgliosis, as we have previously reported [20,22]. pBri treatment resulted in an overall hippocampal (Figure 18) and cortical (Figure 19) reduction in CD45 immunoreactivity for TgSwDI mice of $34 \%$ and $42 \%$, respectively $(P<0.05$ and $P=0.027$ by unpaired one-tailed $t$-tests). For $3 \mathrm{xTg}$ mice, pBri treatment resulted in a $63 \%$ reduction of CD45 immunoreactivity in the hippocampus (Figure 20, $P=0.0035$ by an unpaired two-tailed $t$-test). CD45 immunoreactivity in the cortex of $3 x \mathrm{Tg}$ mice was too low for quantitation.

\section{Quantitation of microhemorrhages by Perl stain in TgSwDI mice}

The number of microhemorrhages in TgSwDI mice was evaluated by Perl staining as we have previously published [22]. No significant differences in microhemorrhages were noted in the pBri-treated TgSwDI mice versus control vehicle-treated Tg mice (Figure 21).

\section{Discussion}

We demonstrated that immunization with a non-selfpeptide in a polymerized, $\beta$-sheet-rich form in two transgenic mice lines, which model either vascular amyloid or tau-related pathology, is able through conformational mimicry to induce an immune response to both pathological A $\beta 42$ and PHF. This extends our previous results that our novel immunomodulatory approach is able to reduce amyloid plaque pathology in APP/PS1 Tg mice
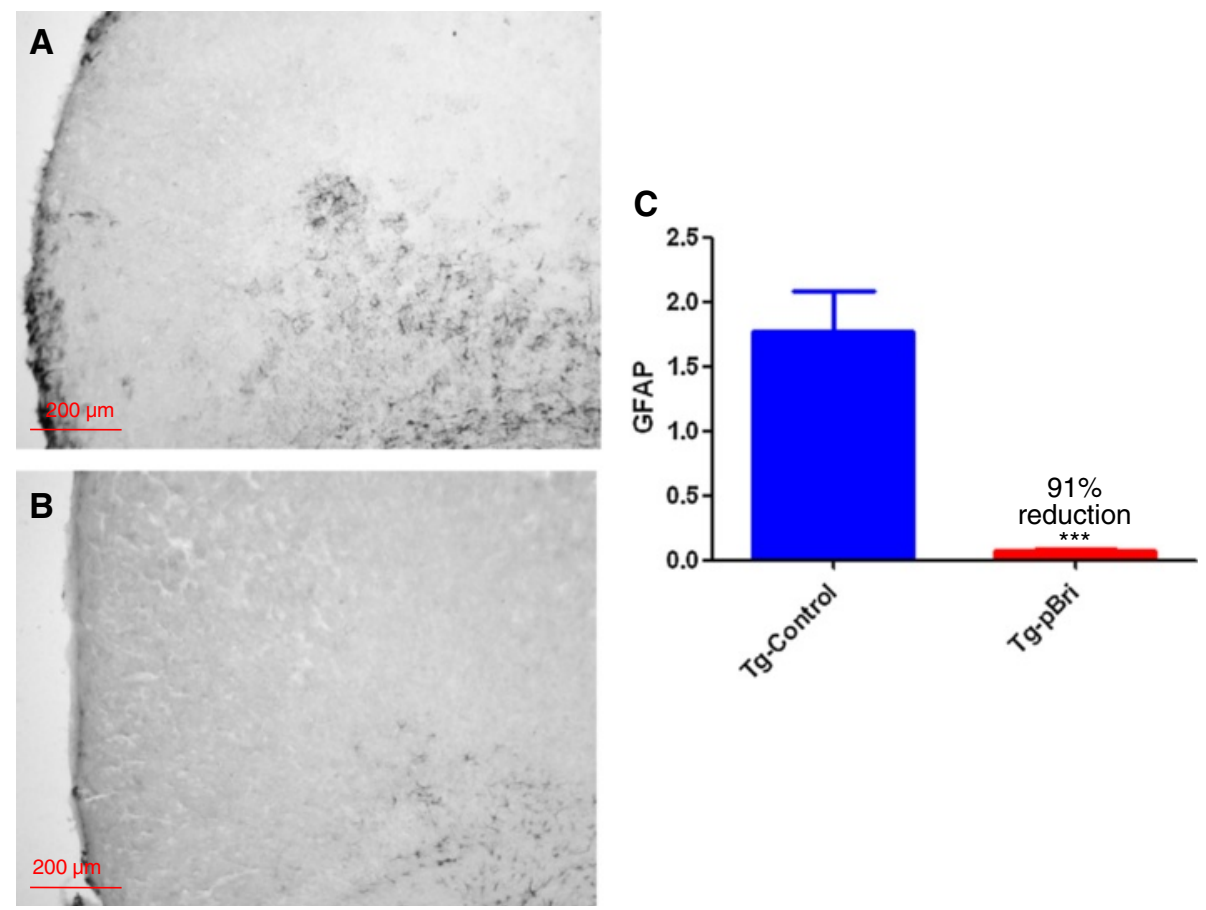

Figure 17 Quantitation of microgliosis in the cortex of $3 x T g$ mice. Microglial burden was analyzed semiquantitatively on a scale of 0 to 4 . Representative brain sections of both (A) vehicle control and (B) pBri-treated Tg mice immunostained with CD45 from the cortex. (C) Bar graph of microglia semiquantitative analysis for the cortex of vehicle control and pBri-vaccinated mice. On average there was a $91 \%$ reduction in the areas occupied by CD45 immunoreactivity accounting for microgliosis ( ${ }^{* *} P=0.0001$ by an unpaired two-tailed $t$-test). GFAP, glial fibrillary acidic protein; Tg, transgenic. 

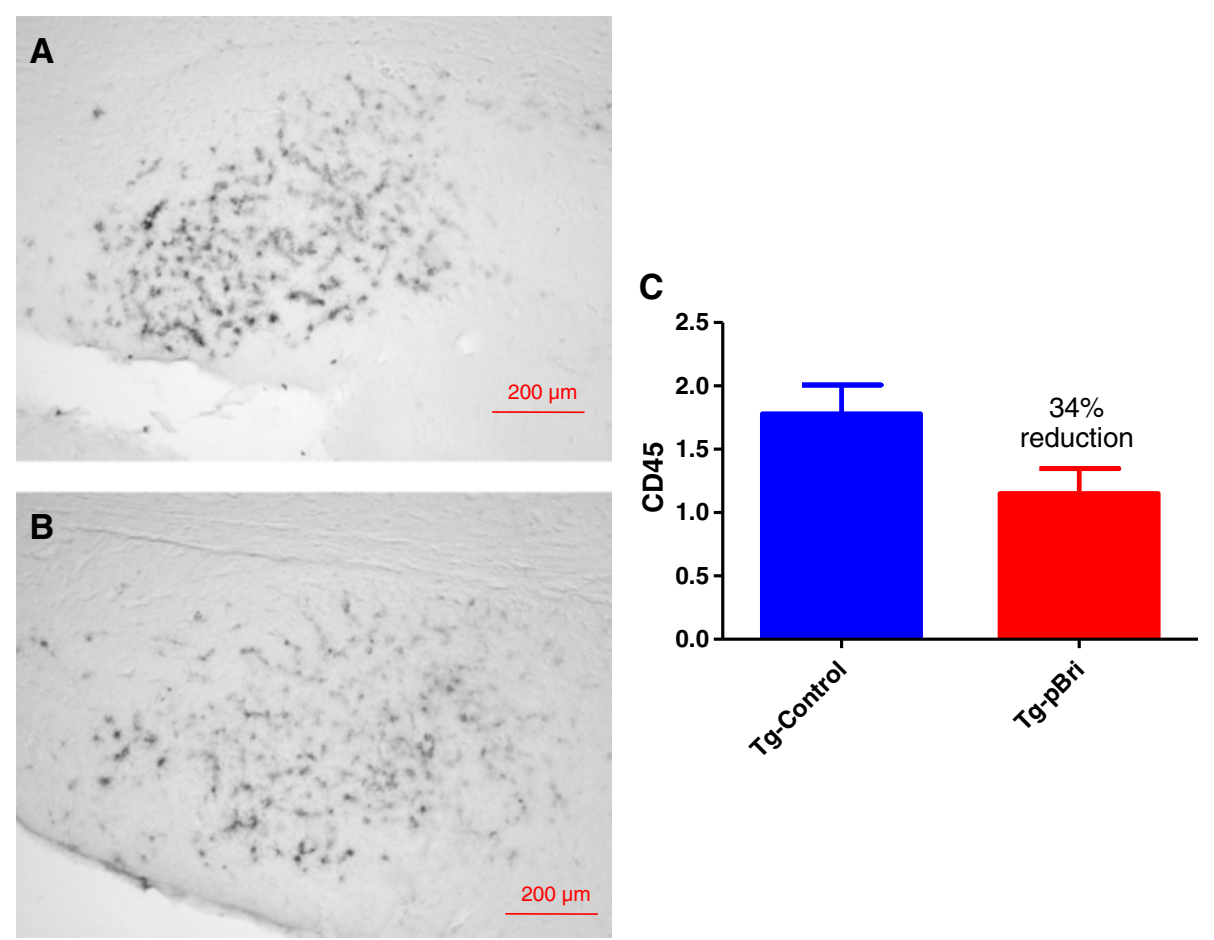

Figure 18 Quantitation of microglial burden in the hippocampus of TgSwDI mice. Microglial burden was analyzed semiquantitatively on a scale of 0 to 4 . Representative brain sections of both (A) vehicle control and (B) pBri-treated Tg mice immunostained with CD45 from the hippocampus. (C) Bar graph of microglia semiquantitative analysis for the hippocampus of vehicle control and pBri-vaccinated mice. On average there was a 34\% reduction in the areas occupied by CD45 immunoreactivity accounting for microgliosis ( $P<0.05$ by an unpaired one-tailed $t$-test). Tg, transgenic.

[16]. Hence, we now show that active immunization with a non-self-antigen in a conformation that is oligomeric can be effective at ameliorating all the cardinal lesions of $\mathrm{AD}$, namely amyloid plaques, congophilic amyloid angiopathy and neurofibrillary tangles, without apparent toxicity. The immunogen we used corresponds to the 13 amino acids of the carboxyl end of the amyloid that is deposited in British amyloidosis, where a missense mutation in a stop codon results in the transcription of a novel intronic sequence $[14,15,38]$. This peptide has no homology to known mammalian proteins, but is highly amyloidogenic [15,39]. This immune response resulted in a clear behavioral rescue in treated TgSwDI and 3xTg mice as they performed similarly to wild-type mice in the radial arm maze. The testing of this cognitive task was not confounded by any differences in the sensorimotor activity between the control and vaccinated mice as shown by the locomotor activity, rotarod and traverse beam testing, where there were no significant differences between treated and control Tg mice for both mouse lines. This behavioral rescue was associated with a marked reduction in A $\beta$-related pathology as determined histologically and biochemically. The anti-A $\beta 42$ and anti-PHF titers our vaccinated mice developed were relatively modest; however, as we and others have suggested, behavioral rescue is most closely linked to oligomer reduction and not with either the degree of amyloid plaque deposition reduction or overall anti-A $\beta$ titer [40-42]. Hence, it is not the absolute degree of the humoral response generated to $A \beta$ or tau epitopes but its quality in terms of effective targeting of toxic species that is likely the most important factor.

The relatively modest titers also reflect two important facts about our approach. First, we made a deliberate choice of aluminum hydroxide (alum) as an adjuvant. Alum is a relatively mild adjuvant but it is approved for human use and is widely used [43]. The majority of immunization studies in AD mouse models have used much stronger adjuvants that are not approved for use in humans [32] and also produce a cytotoxic-prone immune response; hence, the results are more difficult to translate to future human trials. Second, the most toxic forms of both $A \beta$ and tau are thought to be oligomeric $[9,34]$. Importantly we showed that our approach (despite the relatively low titers) was associated with a reduction of these toxic oligomer species, as documented by different assays, one specific to aggregated $A \beta$ species (Figure 9) and others against phosphorylated tau species 

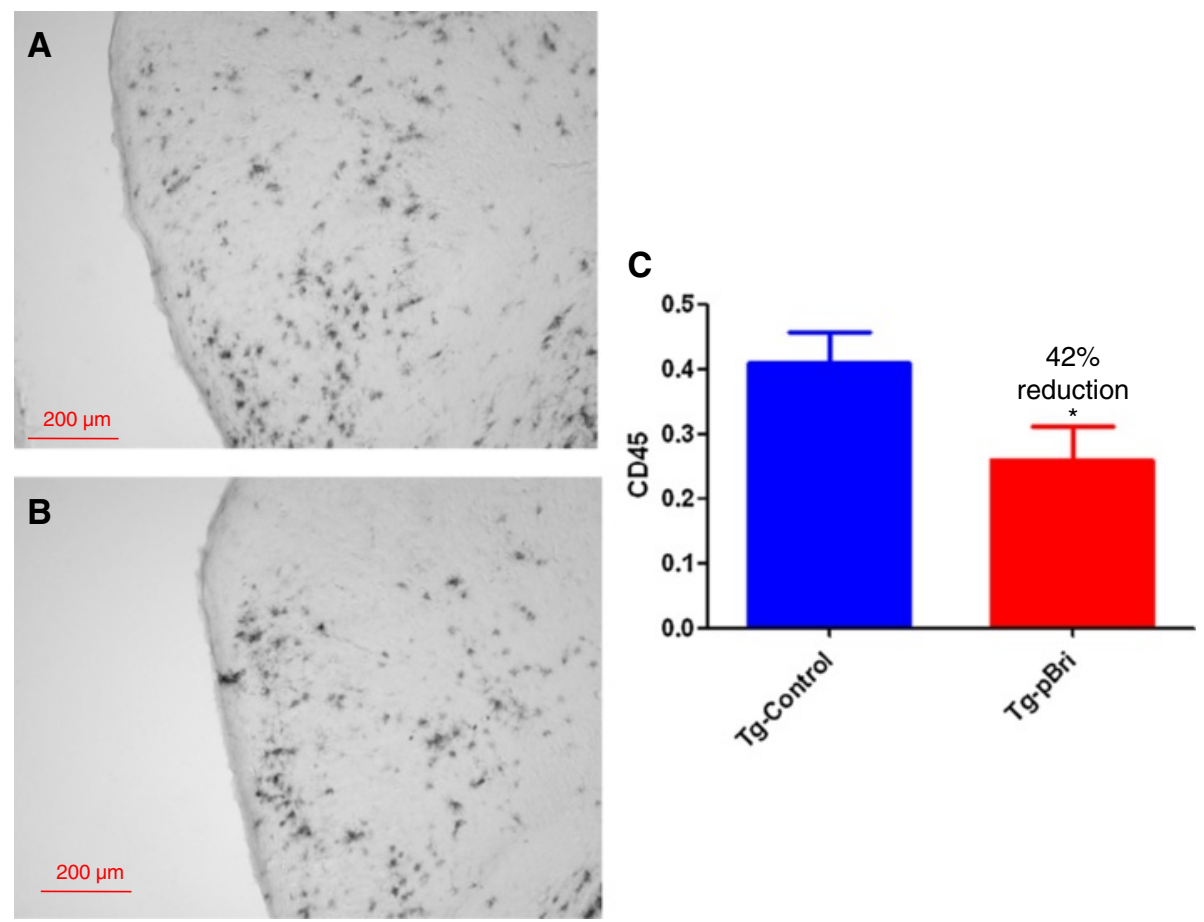

Figure 19 Quantitation of microglial burden in the cortex of TgSwDI mice. Microglial burden was analyzed semiquantitatively on a scale of 0 to 4. Representative brain sections of both (A) vehicle control and (B) pBri-treated Tg mice immunostained with CD45 from the cortex. (C) Bar graph of microglia semiquantitative analysis for the cortex of vehicle control and pBri-vaccinated mice. On average there was a $42 \%$ reduction in the areas occupied by CD45 immunoreactivity accounting for microgliosis ( ${ }^{*} P=0.027$ by an unpaired one-tailed $t$-test). $\mathrm{Tg}$, transgenic.

(Figure 13). This is also consistent with our finding using ELISA for the brain soluble fraction that levels of total A $\beta 42$ species were more significantly reduced compared to total $A \beta 40$ species. It is well known that $A \beta 42$ species are more prone to form oligomers and fibrils. This more specific targeting of $A \beta 42$ species was most notable for the $3 x \mathrm{Tg}$ mice where $\mathrm{A} \beta 42$ levels were reduced by $84 \%$, compared to a $55 \%$ reduction of $A \beta 40$ species (see Figure 8). In addition we demonstrated biochemically that abnormally phosphorylated tau species identified by PHF1 (serine 396 and 202) and by MSD (Thr 231) were reduced by approximately $50 \%$ and $15 \%$, respectively, in the brain soluble fraction, the fraction which contains tau oligomers (Figure 13). Therefore we document the reduction of both $A \beta$ and tau oligomeric species by our immunomodulatory approach. The reduction of tau pathology is likely to be the result of a combination of the direct effects of the sustained conformational antiPHF immune response to oligomeric forms of tau that we found (see Figures 2 and 13), as well as an indirect effect by reducing $A \beta$ oligomers in the $\mathrm{pBri} 3 x \mathrm{xg}$ immunized mice.

The majority of previous active and passive immunization studies in mouse models and all the previous trials in humans have targeted both the normal conformer and the pathological conformer of either $\mathrm{A} \beta$ or tau [44]. This can be problematic as targeting normal $\mathrm{sA} \beta$ may inhibit its known physiological functions such as neuroprotection, modulation of long-term potentiation and innate immunity, and there is the risk of inducing autoimmune complications [45-47]. The targeting of tau by active or passive immunization also carries the risk of neurotoxicity and has an encephalogenic potential $[44,48]$. Our immunomodulation approach greatly reduces the chance of such toxicity as the immunogen is a non-self-peptide in an oligomeric conformation. In an initial human trial of active vaccination, the use of a self-antigen as an immunogen (Aß42) was associated with encephalitis in some $6 \%$ of patients [49], which was linked to excess cell-mediated inflammation $[44,50]$.

An additional autoimmune complication in ongoing human trials of passive immunization using anti-A $\beta$ antibodies has been vasogenic edema or amyloid-related imaging abnormalities (ARIA), a complication that is particularly common in apoE4 carriers [51]. The etiology of ARIA is thought to be directly linked to the removal of amyloid from CAA lesions in blood vessel walls, rendering them more likely to undergo leakage or hemorrhage [52]. CAA occurs in about $98 \%$ of AD patients with approximately $75 \%$ of these cases rated as severe CAA [53-55]. In addition, CAA is present in about $30 \%$ of non-demented elderly individuals [53]. Clinical 

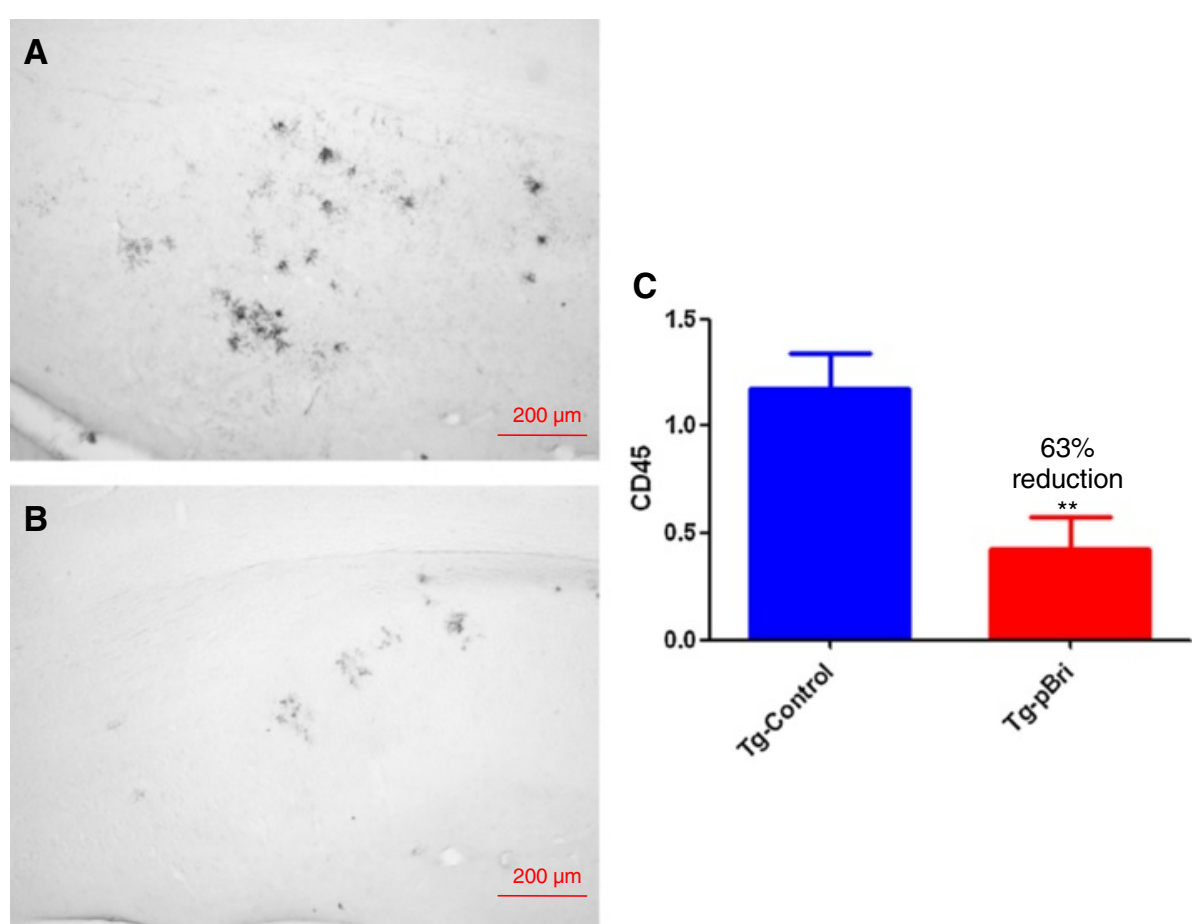

Figure 20 Quantitation of microglial burden in the hippocampus of 3xTg mice. Microglial burden was analyzed semiquantitatively on a scale of 0 to 4. Representative brain sections of both (A) vehicle control and (B) pBri-treated Tg mice immunostained with CD45 from the hippocampus. (C) Bar graph of microglia semiquantitative analysis for the hippocampus of vehicle control and pBri-vaccinated mice. On average there was a 63\% reduction in the areas occupied by CD45 immunoreactivity accounting for microgliosis (** $P=0.0035$ by an unpaired two-tailed $t$-test). $\mathrm{Tg}$, transgenic.
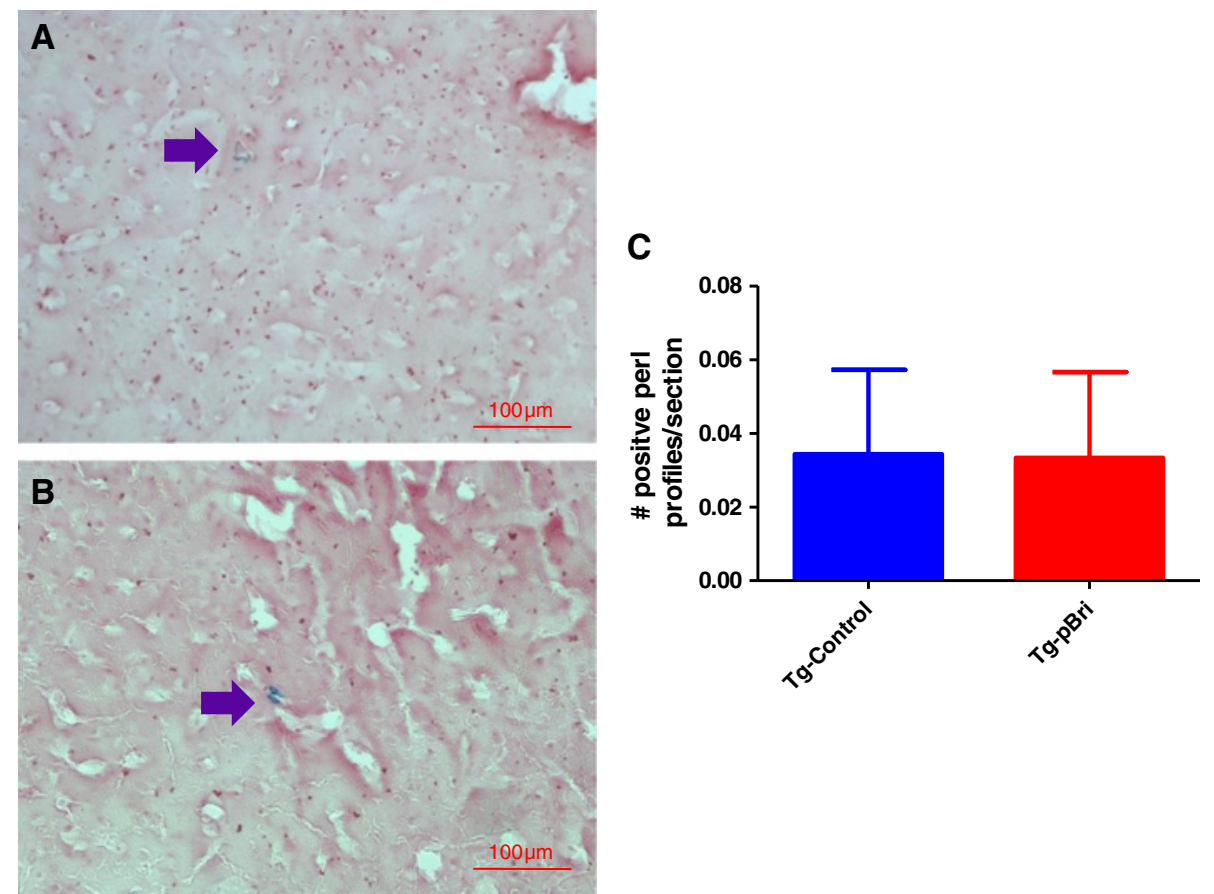

Figure 21 Quantitation of microhemorrhaging in the cortex and hippocampus of TgSwDI mice. The number of positive profiles were quantified per section. Representative Perl-stained brain sections of both (A) vehicle control and (B) pBri-treated Tg mice are shown. Arrows point to Perl positive profiles. (C) Bar graph of Perl stain semiquantitative analysis depicts no significant difference between Tg controls and pBri-treated 3xTg mice. Tg, transgenic. 
studies have shown a strong correlation between cognitive impairment and the presence of CAA [56-58]. Furthermore, CAA is associated with focal ischemia and cerebral hemorrhage due to weakening of vascular walls by amyloid deposits and focal inflammation. Hence, it is important that we found a marked reduction of CAA pathology in TgSwDI mice from $42 \%$ (in the hippocampus) to $72 \%$ (in the amygdala), without an increase in microhemorrhages or inflammatory toxicity. A caveat is that CAA in TgSwDI mice is primarily microvascular, whereas in AD patients amyloid is also found in larger vessels; however, these microvascular amyloid deposits are also associated with hemorrhages and correlate more closely with the presence of dementia [59]. In both $\mathrm{TgSwDI}$ and $3 x \mathrm{Tg}$ mice there were significant reductions of astrocytosis and microgliosis as seen by GFAP and CD45 immunoreactivity. Hence our active immunization approach, which specifically targets pathological conformers only, is effective at lesion reduction without apparent autoimmune complications. It is also notable that our immunization approach uses alum as an adjuvant. Alum has been the most widely used human adjuvant for over 80 years and is regarded as very safe [43]. It predominantly stimulates humoral immunity, and is much less likely to be associated with cytotoxic T-cell responses, which have been linked to toxicity in human $\mathrm{AD}$ vaccination trials $[3,43]$. Our use of alum as an adjuvant facilitates the ease with which our approach could be translated into human trials.

Another significant drawback of the current immunization approaches being tested in humans is that they target only $A \beta$-related pathology. So far none of these trials has seen a robust clinical improvement, leading some to question the amyloid cascade hypothesis $[13,60,61]$. The limited autopsy data from the initial human active vaccination trial targeting $A \beta 42$ showed that patients had partial or near complete plaque removal and a reduction of $A \beta$ load compared to age-matched nonimmunized controls. However, there were no differences between placebo and active immunization groups in the long-term survival outcome, time to severe dementia or in cognitive outcome measurements [60]. Among living patients taking part in a passive immunization trial targeting $A \beta$, a $25 \%$ amyloid reduction versus controls was documented using PET imaging studies, in the absence of measurable cognitive benefits [61]. It has been suggested that the failure to produce clear clinical benefits is related to therapy being started too late in the very long process of $\mathrm{AD}$ pathology accumulation. $\mathrm{A} \beta$ and tau-related pathology begins to develop up to approximately 25 years before the onset of obvious clinical signs of even mild cognitive impairment [62]. Hence, A $\beta$-directed immunotherapy would have to start many years before the patient is symptomatic to have a greater likelihood of being highly efficacious. This suggests that for an immunotherapeutic approach to be effective in symptomatic $\mathrm{AD}$, the intervention should concurrently target both $A \beta$ and tau toxic conformers specifically. There is a growing consensus regarding the importance of specifically targeting both tau and $A \beta$ soluble aggregates therapeutically $[8,9]$. We reported the first active immunization approach that could achieve this goal [16]. Subsequently, another group has developed an analogous approach using a random sequence amyloid oligomer mimetic peptide, confirming the validity of this approach, at least in AD animal models [63,64].

In summary, we found that a novel active immunization approach, using pBri in an oligomer conformation, is able to ameliorate all the cardinal lesions of $\mathrm{AD}$ pathology, amyloid plaques, CAA and NFTs, without apparent toxicity in different animal models that illustrate each of these pathologies. Approaches that target pathological protein conformation have the potential to be effective in a large spectrum of neurodegenerative diseases.

\section{Abbreviations}

$A B$ : amyloid $\beta$; ABri: British amyloidosis; AD: Alzheimer's disease;

ARIA: amyloid-related imaging abnormalities; BBS: borate buffer saline;

Bri: peptide corresponding to the 13 amino acids of the carboxyl end of ABri; BSA: bovine serum albumin; CAA: congophilic amyloid angiopathy;

ECL: enhanced chemiluminescence; EDTA: Ethylenediaminotetraacetic acid disodium salt; EGTA: Ethylene glycol tetraacetic acid tetrasodium salt; GFAP: glial fibrillary acidic protein; MSD: Meso Scale Discovery; NFT: Neurofibrillary tangles; OD: optical density; pBri: polymerized British amyloidosis carboxi-terminal 13 amino acid peptide; PHF: paired helical filaments; SDS: sodium-dodecyl sulfate; TBS-T: $50 \mathrm{mM}$ tris-buffer-saline- $0.1 \%$ Tween 20; Tg: transgenic; TMB: tetramethylbenzidine.

\section{Competing interests}

The authors declare that they have no competing interests.

\section{Authors' contributions}

FG and TW designed the experiments, analyzed the results and wrote the paper. FG carried out the antigen preparations, and animal inoculations. KH participated in all the histochemical experiments and helped prepare figures. DP participated in biochemical experiments, ELISAs, blots and helped design some of the figures. KW participated in ELISAs, blots, immunohistochemistry, biochemistry and some behavioral testing. YJ carried out most of the sensorimotor, all locomotor and radial arm maze experiments. YS took care of the experimental animals during the course of the experiments and tested the transgenic status of the animals. PM performed A $\beta$ peptide level analysis. TW supervised all experiments. All authors read and approved the final manuscript.

\section{Acknowledgements}

This manuscript was supported by NIH grants NS073502, AG20245 and AG08051. It was also supported by the Alzheimer's Disease Association.

\section{Author details}

'Department of Neurology, New York University School of Medicine, 550 First Avenue, New York, NY 10016, USA. ${ }^{2}$ Department of Pathology, New York University School of Medicine, 550 First Avenue, New York, NY 10016, USA. ${ }^{3}$ Department of Psychiatry, New York University School of Medicine, 550 First Avenue, New York, NY 10016, USA. ${ }^{4}$ New York State Institute for Basic Research in Developmental Disabilities, 1050 Forest Hill Rd., Staten Island, NY 10314, USA. ${ }^{5}$ Department of Neurology, Tianjin Huanhu Hospital, Tianjin, China. ${ }^{6} \mathrm{New}$ York University School of Medicine, Alexandria ERSP, Rm 802, 450 East 29th Street, New York, NY 10016, USA. 
Received: 21 October 2013 Accepted: 23 November 2013

Published: 13 December 2013

\section{References}

1. Gaugler J, James B, Johnson T, Scholz K, Weuve J: Alzheimer's Disease Facts and Figures 2013. Alzheimer's Disease Association; 2013. on line source: http://www.alz.org/downloads/facts_figures_2013.pdf.

2. Ozudogru SN, Lippa CF: Disease modifying drugs targeting beta-amyloid. Am J Alzheimers Dis Other Demen 2012, 27:296-300.

3. Wisniewski T: Active immunotherapy for Alzheimer's disease. Lancet Neurol 2012, 11:571-572

4. Grill JD, Cummings JL: Current therapeutic targets for the treatment of Alzheimer's disease. Expert Rev Neurother 2010, 10:711-728.

5. Morgan D: Immunotherapy for Alzheimer's disease. J Intern Med 2011, 269:54-63.

6. Huang Y, Mucke L: Alzheimer mechanisms and therapeutic strategies. Cell 2012, 148:1204-1222.

7. Nelson PT, Alafuzoff I, Bigio EH, Bouras C, Braak H, Cairns N, Davies P, Tredici KD, Duyckaerts C, Frosch MP, Hof PR, Hulette C, Hyman BT, Iwatsubo T, Jellinger KA, Jicha GA, Kovari E, Kukull WA, Leverenz JB, Love S, Mackenzie IR, Mann DM, Masliah E, McKee A, Montine TJ, Morris JC, Schneider JA, Sonnen JA, Thal DR, Trojanowski JQ, Troncoso JC, Wisniewski T, Woltjer RL, Beach TG: Correlation of Alzheimer's disease neuropathologic changes with cognitive status: a review of the literature. J Neuropath Exp Neurol 2012, 71:362-381.

8. Hefti F, Goure WF, Jerecic J, Iverson KS, Walicke PA, Krafft GA: The case for soluble Abeta oligomers as a drug target in Alzheimer's disease. Trends Pharmacol Sci 2013, 34:261-266.

9. Castillo-Carranza DL, Lasagna-Reeves CA, Kayed R: Tau aggregates as immunotherapeutic targets. Front Biosci (Schol Ed) 2013, 5:426-438.

10. Ashe KH, Aguzzi A: Prions, prionoids and pathogenic proteins in Alzheimer disease. Prion 2013, 7:55-59.

11. Wisniewski T, Boutajangout A: Immunotherapeutic approaches for Alzheimer's disease in transgenic mouse models. Brain Struct Funct 2010 214:201-218.

12. Wisniewski T, Chabalgoity JA, Goni F: Is vaccination against transmissible spongiform encephalopathies feasible? OIE Sci Tech Rev 2007, 26:243-251.

13. Mullane K, Williams M: Alzheimer's therapeutics: continued clinical failures question the validity of the amyloid hypothesis - but what lies beyond? Biochem Pharmacol 2013, 85:289-305.

14. Vidal R, Frangione B, Rostagno A, Mead S, Revesz T, Plant G, Ghiso J: A stop-codon mutation in the BRI gene associated with familial British dementia. Nature 1999, 399:776-781.

15. Rostagno A, Tomidokoro Y, Lashley T, Ng D, Plant G, Holton J, Frangione B, Revesz T, Ghiso J: Chromosome 13 dementias. Cell Mol Life Sci 2005, 62:1814-1825.

16. Goni F, Prelli F, Ji Y, Scholtzova H, Yang J, Sun Y, Liang FX, Kascsak R, Kascsak R, Mehta P, Wisniewski T: Immunomodulation targeting abnormal protein conformation reduces pathology in a mouse model of Alzheimer's disease. PLOS ONE 2010, 5:e13391.

17. Schnabel J: Vaccines: chasing the dream. Nature 2011, 475:S18-S19.

18. Davis J, Xu F, Deane R, Romanov G, Previti ML, Zeigler K, Zlokovic BV, van Nostrand WE: Early-onset and robust cerebral microvascular accumulation of amyloid beta-protein in transgenic mice expressing low levels of a vasculotropic Dutch/lowa mutant form of amyloid betaprotein precursor. J Biol Chem 2004, 279:20296-20306.

19. Oddo S, Caccamo A, Shepherd JD, Murphy MP, Golde TE, Kayed R, Metherate R, Mattson MP, Akbari Y, LaFerla FM: Triple-transgenic model of Alzheimer's disease with plaques and tangles: intracellular $A \beta$ and synaptic dysfunction. Neuron 2003, 39:409-421.

20. Liu S, Breitbart A, Sun Y, Mehta PD, Boutajangout A, Scholtzova $H$, Wisniewski T: Blocking the apolipoprotein E/amyloid $\beta$ interaction in triple transgenic mice ameliorates Alzheimer's disease related amyloid $\beta$ and tau pathology. J.Neurochem 2013: . epub October 10.

21. Miao J, Xu F, Davis J, Otte-Holler I, Verbeek MM, van Nostrand WE: Cerebral microvascular amyloid beta protein deposition induces vascular degeneration and neuroinflammation in transgenic mice expressing human vasculotropic mutant amyloid beta precursor protein. Am J Pathol 2005, 167:505-515.

22. Yang J, Ji Y, Mehta P, Bates KA, Sun Y, Wisniewski T: Blocking the apolipoprotein E/amyloid $\beta$ interaction reduces fibrillar vascular amyloid deposition and cerebral microhemorrhages in TgSwDI mice. J Alzheimers Dis 2011, 24:269-285.

23. Sadowski M, Pankiewicz J, Scholtzova H, Mehta P, Prelli F, Quartermain D Wisniewski T: Blocking the apolipoprotein E/amyloid $\beta$ interaction reduces the parenchymal and vascular amyloid-b deposition and prevents memory deficit in AD transgenic mice. Proc Natl Acad Sci USA 2006, 103:18787-18792.

24. Scholtzova H, Kascsak RJ, Bates KA, Boutajangout A, Kerr DJ, Meeker HC, Mehta PD, Spinner DS, Wisniewski T: Induction of Toll-like receptor 9 signaling as a method for ameliorating Alzheimer's disease related pathology. J Neurosci 2009, 29:1846-1854.

25. Otvos L Jr, Feiner L, Lang E, Szendrei Gl, Goedert M, Lee VM: Monoclonal antibody PHF-1 recognizes tau protein phosphorylated at serine residues 396 and 404. J Neurosci Res 1994, 39:669-673.

26. Goedert $M$, Jakes $R$, Vanmechelen E: Monoclonal antibody AT8 recognises tau protein phosphorylated at both serine 202 and threonine 205. Neurosci Lett 1995, 189:167-169.

27. Kutner KC, Erlanger DM, Tsai J, Jordan B, Relkin NR: Lower cognitive performance of older football players possessing apolipoprotein $\mathrm{E}$ epsilon4. Neurosurgery 2000, 47:651-657.

28. Morgan D, Gordon MN, Tan J, Wilcock D, Rojiani AM: Dynamic complexity of the microglial activation response in transgenic models of amyloid deposition: implications for Alzheimer therapeutics. J Neuropathol Exp Neurol 2005, 64:743-753.

29. Scholtzova H, Wadghiri YZ, Douadi M, Sigurdsson EM, Li Y, Quartermain D, Banerjee $P$, Wisniewski T: A NMDA receptor antagonist leads to behavioral improvement and amyloid reduction in Alzheimer's disease model transgenic mice shown by micro-magnetic resonance imaging. J Neurosci Res 2008, 86:2784-2791.

30. Dhenain $M$, Delatour B, Walczak C, Volk A: Passive staining: a novel ex vivo MRI protocol to detect amyloid deposits in mouse models of Alzheimer's disease. Magn Reson Med 2006, 55:687-693.

31. Sanchez-Ramos J, Song S, Sava V, Catlow B, Lin X, Mori T, Cao C, Arendash GW: Granulocyte colony stimulating factor decreases brain amyloid burden and reverses cognitive impairment in Alzheimer's mice. Neuroscience 2009, 163:55-72

32. Wisniewski T, Sigurdsson EM: Murine models of Alzheimer's disease and their use in developing immunotherapies. Biochim Biophys Acta Mol Basis Dis 1802, 2010:847-859.

33. Gordon MN, Holcomb LA, Jantzen PT, DiCarlo G, Wilcock D, Boyett KW, Connor K, Melachrino J, O'Callaghan JP, Morgan D: Time course of the development of Alzheimer-like pathology in the doubly transgenic PS1 + APP mouse. Exp Neurol 2002, 173:183-195.

34. Lublin AL, Gandy S: Amyloid-beta oligomers: possible roles as key neurotoxins in Alzheimer's disease. Mt Sinai J Med 2010, 77:43-49.

35. Kuszczyk MA, Sanchez S, Pankiewicz J, Kim J, Duszczyk M, Guridi M, Asuni AA, Sullivan PM, Holtzman DM, Sadowski MJ: Blocking the interaction between apolipoprotein $\mathrm{E}$ and Abeta reduces intraneuronal accumulation of Abeta and inhibits synaptic degeneration. Am J Pathol 2013, 182:1750-1768.

36. Fukumoto H, Tokuda T, Kasai T, Ishigami N, Hidaka H, Kondo M, Allsop D, Nakagawa M: High-molecular-weight beta-amyloid oligomers are elevated in cerebrospinal fluid of Alzheimer patients. FASEB J 2010, 24:2716-2726

37. Hunter JM, Bowers WJ, Maarouf CL, Mastrangelo MA, Daugs ID, Kokjohn TA, Kalback WM, Luehrs DC, Valla J, Beach TG, Roher AE: Biochemical and morphological characterization of the AbetaPP/PS/tau triple transgenic mouse model and its relevance to sporadic Alzheimer's disease. J Alzheimers Dis 2011, 27:361-376.

38. Ghiso J, Vidal R, Rostagno A, Miravalle L, Holton JL, Mead S, Revesz T, Plant $G$, Frangione B: Amyloidogenesis in familial British dementia is associated with a genetic defect on chromosome 13. Molecular Basis of Dementia 2000, 920:84-92.

39. Srinivasan R, Jones EM, Liu K, Ghiso J, Marchant RE, Zagorski MG: $\mathrm{pH}$-dependent amyloid and protofibril formation by the ABri peptide of familial British dementia. J Mol Biol 2003, 333:1003-1023.

40. Janus C, Pearson J, McLaurin J, Mathews PM, Jiang Y, Schmidt SD, Chisht MA, Horne P, Heslin D, French J, Mount HT, Nixon RA, Mercken M, Bergeron C, Fraser PE, George-Hyslop P, Westaway D: A $\beta$ peptide immunization reduces behavioural impairment and plaques in a model of Alzheimer's disease. Nature 2000, 408:979-982. 
41. Morgan D, Diamond DM, Gottschall PE, Ugen KE, Dickey C, Hardy J, Duff K, Jantzen P, DiCarlo G, Wilcock D, Connor K, Hatcher J, Hope C, Gordon M, Arendash GW: $A \beta$ peptide vaccination prevents memory loss in an animal model of Alzheimer's disease. Nature 2000, 408:982-985.

42. Asuni A, Boutajangout A, Scholtzova H, Knudsen E, Li Y, Quartermain D, Frangione $B$, Wisniewski $T$, Sigurdsson $E M$ : $A \beta$ derivative vaccination in alum adjuvant prevents amyloid deposition and does not cause brain microhemorrhages in Alzheimer's model mice. Eur J Neurosci 2006, 24:2530-2542.

43. Kool M, Fierens $K$, Lambrecht BN: Alum adjuvant: some of the tricks of the oldest adjuvant. J Med Microbiol 2012, 61:927-934.

44. Panza F, Frisardi V, Solfrizzi V, Imbimbo BP, Logroscino G, Santamato A Greco A, Seripa D, Pilotto A: Immunotherapy for Alzheimer's disease: from anti-beta-amyloid to tau-based immunization strategies. Immunotherapy 2012, 4:213-238.

45. Puzzo D, Privitera L, Leznik E, Fa M, Staniszewski A, Palmeri A, Arancio O: Picomolar amyloid-beta positively modulates synaptic plasticity and memory in hippocampus. J Neurosci 2008, 28:14537-14545.

46. Giuffrida ML, Caraci F, Pignataro B, Cataldo S, De BP, Bruno V, Molinaro G, Pappalardo G, Messina A, Palmigiano A, Garozzo D, Nicoletti F, Rizzarelli E, Copani A: Beta-amyloid monomers are neuroprotective. J Neurosci 2009, 29:10582-10587

47. Soscia SJ, Kirby JE, Washicosky KJ, Tucker SM, Ingelsson M, Hyman B, Burton MA, Goldstein LE, Duong S, Tanzi RE, Moir RD: The Alzheimer's diseaseassociated amyloid beta-protein is an antimicrobial peptide. PLOS ONE 2010, 5:e9505

48. Rosenmann H, Grigoriadis N, Karussis D, Boimel M, Touloumi O, Ovadia H, Abramsky O: Tauopathy-like abnormalities and neurologic deficits in mice immunized with neuronal tau protein. Arch Neurol 2006 63:1459-1467.

49. Gilman S, Koller M, Black RS, Jenkins L, Griffith SG, Fox NC, Eisner L, Kirby L, Boada Rovira M, Forette F, Orgogozo JM: Clinical effects of $A \beta$ immunization (AN1792) in patients with $A D$ in an interrupted trial. Neurol 2005, 64:1553-1562.

50. Wisniewski T, Boutajangout A: Vaccination as a therapeutic approach for Alzheimer's disease. Mt Sinai J Med 2010, 77:17-31.

51. Sperling RA, Jack CR Jr, Black SE, Frosch MP, Greenberg SM, Hyman BT, Scheltens P, Carrillo MC, Thies W, Bednar MM, Black RS, Brashear HR, Grundman M, Siemers ER, Feldman HH, Schindler RJ: Amyloid-related imaging abnormalities in amyloid-modifying therapeutic trials: Recommendations from the Alzheimer's Association Research Roundtable Workgroup. Alzheimers Dement 2011, 7:367-385.

52. Zago W, Schroeter S, Guido T, Khan K, Seubert P, Yednock T, Schenk D, Gregg KM, Games D, Bard F, Kinney GG: Vascular alterations in PDAPP mice after anti-Abeta immunotherapy: Implications for amyloid-related imaging abnormalities. Alzheimers Dement 2013, 9:S105-S115.

53. Jellinger KA: Prevalence and impact of cerebrovascular lesions in Alzheimer and Lewy body diseases. Neurodegener Dis 2010, 7:112-115.

54. Jellinger KA: Alzheimer disease and cerebrovascular pathology: an update. J Neural Transm 2002, 109:813-836.

55. Jellinger KA, Attems J: Prevalence and pathogenic role of cerebrovascular lesions in Alzheimer disease. J Neurol Sci 2005, 229-230:37-41.

56. Pfeifer LA, White LR, Ross GW, Petrovitch H, Launer LJ: Cerebral amyloid angiopathy and cognitive function: the HAAS autopsy study. Neurol 2002, 58:1629-1634

57. Attems J, Quass M, Jellinger KA, Lintner F: Topographical distribution of cerebral amyloid angiopathy and its effect on cognitive decline are influenced by Alzheimer disease pathology. J Neurol Sci 2007, 257:49-55.

58. Greenberg SM, Gurol ME, Rosand J, Smith EE: Amyloid angiopathy-related vascular cognitive impairment. Stroke 2004, 35:2616-2619.

59. Attems J, Jellinger KA: Only cerebral capillary amyloid angiopathy correlates with Alzheimer pathology - a pilot study. Acta Neuropathol (Berl) 2004, 107:83-90.

60. Holmes C, Boche D, Wilkinson D, Yadegarfar G, Hopkins V, Bayer A, Jones RW, Bullock R, Love S, Neal JW, Zotova E, Nicoll JAR: Long term effects of A 342 immunization in Alzheimer's disease: immune response, plaque removal and clinical function. Lancet 2008, 372:216-223.

61. Rinne JO, Brooks DJ, Rossor MN, Fox NC, Bullock R, Klunk WE, Mathis CA, Blennow K, Barakos J, Okello AA, de Llano SRM, Liu E, Koller M, Gregg KM, Schenk D, Black R, Grundman M: (11)C-PiB PET assessment of change in fibrillar amyloid-beta load in patients with Alzheimer's disease treated with bapineuzumab: a phase 2, double-blind, placebo-controlled, ascending-dose study. Lancet Neurol 2010, 9:363-372.

62. Yoshiyama Y, Lee VM, Trojanowski JQ: Therapeutic strategies for tau mediated neurodegeneration. J Neurol Neurosurg Psychiatry 2013, 84:784-795

63. Rasool S, Albay R III, Martinez-Coria H, Breydo L, Wu J, Milton S, Misra S, Tran A, Pensalfini A, LaFerla F, Kayed R, Glabe CG: Vaccination with a non-human random sequence amyloid oligomer mimic results in improved cognitive function and reduced plaque deposition and micro hemorrhage in Tg2576 mice. Mol Neurodegener 2012, 7:37.

64. Rasool S, Martinez-Coria H, Milton S, Glabe CG: Nonhuman amyloid oligomer epitope reduces Alzheimer's-like neuropathology in 3xTg-AD transgenic mice. Mol Neurobiol 2013, 48:931-940.

\section{doi:10.1186/1742-2094-10-150}

Cite this article as: Goñi et al:: Immunomodulation targeting of both $A \beta$ and tau pathological conformers ameliorates Alzheimer's disease pathology in TgSwDI and 3xTg mouse models. Journal of Neuroinflammation 2013 10:150.

\section{Submit your next manuscript to BioMed Central and take full advantage of:}

- Convenient online submission

- Thorough peer review

- No space constraints or color figure charges

- Immediate publication on acceptance

- Inclusion in PubMed, CAS, Scopus and Google Scholar

- Research which is freely available for redistribution

Submit your manuscript at www.biomedcentral.com/submit
C BioMed Central 